\title{
RNA Dysregulation in Amyotrophic Lateral Sclerosis
}

\author{
Zoe Butti and Shunmoogum A. Patten* \\ INRS-Institut Armand-Frappier, National Institute of Scientific Research, Laval, QC, Canada
}

Amyotrophic lateral sclerosis (ALS) is the most common adult-onset motor neuron disease and is characterized by the degeneration of upper and lower motor neurons. It has become increasingly clear that RNA dysregulation is a key contributor to ALS pathogenesis. The major ALS genes SOD1, TARDBP, FUS, and C9orf72 are involved in aspects of RNA metabolism processes such as mRNA transcription, alternative splicing, RNA transport, mRNA stabilization, and miRNA biogenesis. In this review, we highlight the current understanding of RNA dysregulation in ALS pathogenesis involving these major ALS genes and discuss the potential of therapeutic strategies targeting disease RNAs for treating ALS.

Keywords: ALS (amyotrophic lateral sclerosis), FUS, C9orf72, TDP-43, RNA processing, RNAi (RNA interference), antisense oligonucleotide-drug conjugates

\section{OPEN ACCESS}

Edited by:

Pascal Chartrand,

Université de Montréal, Canada

Reviewed by:

Jean-Marc Gallo,

King's College London,

United Kingdom

Rita Sattler,

Barrow Neurological Institute (BNI),

United States

*Correspondence:

Shunmoogum A. Patten

kessen.patten@iaf.inrs.ca

Specialty section:

This article was submitted to Genetic Disorders,

a section of the journal

Frontiers in Genetics

Received: 13 August 2018 Accepted: 20 December 2018 Published: 22 January 2019

Citation:

Butti $Z$ and Patten SA (2019) RNA

Dysregulation in Amyotrophic Lateral

Sclerosis. Front. Genet. 9:712.

doi: 10.3389/fgene.2018.00712

\section{INTRODUCTION}

Amyotrophic lateral sclerosis (ALS) is a progressive and fatal neurodegenerative disorder of motor function. It is characterized by the selective degeneration of the lower and upper motor neurons. Among the symptoms of this disease are progressive muscle weakness and paralysis, swallowing difficulties and breathing impairment due to respiratory muscle weakness that ultimately causes death, usually within 2-5 years following clinical diagnosis (Kiernan et al., 2011). Though most cases of ALS are sporadic, some families (10\%) demonstrate a clinically indistinguishable form of ALS with clear Mendelian inheritance and high penetrance (Pasinelli and Brown, 2006). Treatments to slow the progression of ALS to date remains riluzole (Bensimon et al., 1994) and edaravone (Abe et al., 2014) but they are only modestly effective. However, in the past couple years, there has been a real encouragement in witnessing potentially efficacious treatments, such as Masitinib and Pimozide (Trias et al., 2016; Patten et al., 2017; Petrov et al., 2017) claiming to demonstrate clinical benefit. Furthermore, RNA-targeted therapies are currently intensively being evaluated as potential strategies for treating this ALS (Schoch and Miller, 2017; Mathis and Le Masson, 2018). There is indeed hope to have new and potentially more effective treatment options available for ALS in the near future.

Mutations in over more than 20 genes contribute to the etiology of ALS (Chia et al., 2018) (Table 1). Amongst these genes, the major established causal ALS genes are SOD1 (Cu- $\mathrm{Zn}$ superoxide dismutase 1), TARDBP (transactive response DNA Binding protein $43 \mathrm{kDa}$ ), FUS (fused in sarcoma) and hexanucleotide expansion repeat in Chromosome 9 Open Reading Frame 72 (C9ORF72). These genetic discoveries have led to the development of animal models (Julien and Kriz, 2006; Kabashi et al., 2010; Patten et al., 2014; Picher-Martel et al., 2016) that permitted the identification of key pathobiological insights. Currently, RNA dysregulation appears to be a major contributor to ALS pathogenesis. Indeed, TDP-43 and FUS are deeply involved in RNA processing such as transcription, alternative splicing and microRNA (miRNA) biogenesis 
(Buratti et al., 2004, 2010; Polymenidou et al., 2012). Mutations in C9ORF72, lead to a toxic mRNA gain of function through RNA foci formation, and the subsequent sequestration in stress granules and altered activity of RNA-binding proteins (Barker et al., 2017). In addition to the major ALS genes, other ALS genes including ataxin-2 (ATXN2) (Ostrowski et al., 2017), TATA-box binding protein associated factor 15 (TAF15) (Ibrahim et al., 2013), heterogeneous nuclear ribonucleoprotein A1 (hnRNPA1) (Dreyfuss et al., 1993), heterogeneous nuclear ribonucleoprotein A2 B1 (hnRNPA2 B1) (Alarcon et al., 2015), matrin 3 (MATR3) (Coelho et al., 2015), Ewing's sarcoma breakpoint region 1 (EWSR1) (Duggimpudi et al., 2015), T-cell-restricted intracellular antigen-1 (TIA1) (Forch et al., 2000), senataxin (SETX) and angiogenin (ANG) (Yamasaki et al., 2009), play critical role in RNA processing (Table $\mathbf{1}$ ).

In this review, we focus on the four major ALS-associated genes (SOD1, TARDBP, FUS, and C9orf72) and present how they play critical roles in various RNA pathways. We particularly highlight recent developments on the dysregulation of RNA

TABLE 1 | ALS genes and their involvement in RNA processing.

\begin{tabular}{|c|c|c|}
\hline Gene & Protein encoded & $\begin{array}{l}\text { Regulation of RNA } \\
\text { processing }\end{array}$ \\
\hline SOD1 & Superoxide dismutase 1 & Yes \\
\hline$T A R D B P$ & Tar-DNA-binding protein-43 & Yes \\
\hline FUS & Fused in sarcoma & Yes \\
\hline C9orf72 & C9orf72 & Yes \\
\hline ATXN2 & Ataxin-2 & Yes \\
\hline TAF15 & $\begin{array}{l}\text { TATA-box binding protein associated } \\
\text { factor } 15\end{array}$ & Yes \\
\hline UBQLN2 & Ubiquilin 2 & No \\
\hline OPTN & Optineurin & No \\
\hline KIF5A & Kinesin family member $5 \mathrm{~A}$ & No \\
\hline hnRNPA1 & $\begin{array}{l}\text { Heterogeneous nuclear } \\
\text { ribonucleoprotein } \mathrm{A} 1\end{array}$ & Yes \\
\hline hnRNPA2 B1 & $\begin{array}{l}\text { Heterogeneous nuclear } \\
\text { ribonucleoprotein A2/B1 }\end{array}$ & Yes \\
\hline MATR3 & Matrin 3 & Yes \\
\hline $\mathrm{CHCHD10}$ & $\begin{array}{l}\text { Coiled-coil-helix-coiled-coil-helix } \\
\text { domain containing } 10\end{array}$ & No \\
\hline EWSR1 & EWS RNA binding protein 1 & Yes \\
\hline TIA1 & $\begin{array}{l}\text { TIA1 cytotoxic granule associated RNA } \\
\text { binding protein }\end{array}$ & Yes \\
\hline SETX & Senataxin & Yes \\
\hline$A N G$ & Angiogenin & Yes \\
\hline CCNF & Cyclin F & No \\
\hline NEK1 & NIMA related kinase 1 & No \\
\hline TBK1 & TANK binding kinase 1 & No \\
\hline VCP & Valosin containing protein & No \\
\hline SQSTM1 & Sequestosome 1 & No \\
\hline PFN1 & Profilin 1 & No \\
\hline TUBB4A & Tubulin beta 4A class IVa & No \\
\hline CHMP2B & Charged multivesicular body protein 2B & No \\
\hline SPG11 & Spatacsin vesicle trafficking associated & No \\
\hline ALS2 & $\begin{array}{l}\text { Alsin Rho guanine nucleotide exchange } \\
\text { factor }\end{array}$ & No \\
\hline
\end{tabular}

pathways (Figure 1) as a major contributor to ALS pathogenesis and discuss the potential of RNA-targeted therapies for ALS.

\section{TAR DNA BINDING PROTEIN (TDP-43)}

A major advance in our understanding of cellular mechanisms in ALS came from the identification of causative mutations in the TARDBP gene (Kabashi et al., 2008; Sreedharan et al., 2008). This gene encodes for the evolutionarily conserved RNA/DNA binding protein, TDP-43. It is a protein that is normally nuclear, however, in cases of TARDBP mutations, it is mislocalized to the cytoplasm and forms aggregates (Van Deerlin et al., 2008; Winton et al., 2008b). It is found in the pathological aggregates in motor neurons in the majority of cases of ALS (Neumann et al., 2006). It is believed that TDP-43 aggregation leads to a gain of toxicity and its nuclear depletion results to a loss of function of TDP-43. Indeed, several studies have demonstrated that either overexpression or knockdown of TDP-43 causes neurodegeneration and ALS phenotypes (Kabashi et al., 2010; Stallings et al., 2010; Iguchi et al., 2013; Yang et al., 2014). For instance, the expression of the mutant TDP-43 ${ }^{\mathrm{A} 315 \mathrm{~T}}$ in the C. elegans' GABAergic motor neurons results in age-dependent motility defects and neurodegeneration (Vaccaro et al., 2012). In drosophila, overexpression of TDP-43 in motor neurons was found to cause cytoplasmic accumulation of TDP-43 aggregates, neuromuscular junction (NMJ) morphological defects and cell death (Li et al., 2010). Similarly, the loss of TDP-43 reduced locomotion and lifespan (Feiguin et al., 2009; Diaper et al., 2013). Implications of TDP-43 loss and toxic gain-of-function in impaired motility, neurodegeneration and survival were further confirmed in higher model systems such as the zebrafish (Kabashi et al., 2010) and mice (Wegorzewska et al., 2009; Iguchi et al., 2013). Altogether, these reports strongly suggest that alterations in the level of TDP-43 are detrimental to neuronal function and survival.

TDP-43 contains two RNA recognition motifs (RRM1-2), a glycine rich domain in the C-terminus and nuclear localization and export signals (NLS and NES) (Buratti and Baralle, 2001; Winton et al., 2008a). TDP-43 plays a major role in multiple steps of RNA processing such as splicing, RNA stability and mRNA transport (Buratti and Baralle, 2008). For instance, TDP43 has been shown to bind to mRNA and regulate the expression of other proteins implicated in ALS and other neurodegenerative diseases such as FUS, Tau, ATXN 2 and progranulin (Polymenidou et al., 2011; Sephton et al., 2011; Tollervey et al., 2011). This suggests that TDP-43 may be a central component in the pathogenesis of several neurodegenerative conditions (Polymenidou et al., 2011). By RNA-seq analysis, Polymenidou et al. (2011) reported that TDP-43 is required for regulating the expression of 239 mRNAs, many of those encoding synaptic proteins. Several independent studies have corroborated that TDP-43 plays an important role in regulating genes involved in synaptic formation and function and in the regulation of neurotransmitter processes (Godena et al., 2011; Sephton et al., 2011; Colombrita et al., 2012; Narayanan et al., 2013; Chang et al., 2014). Examples of such genes are neurexin 


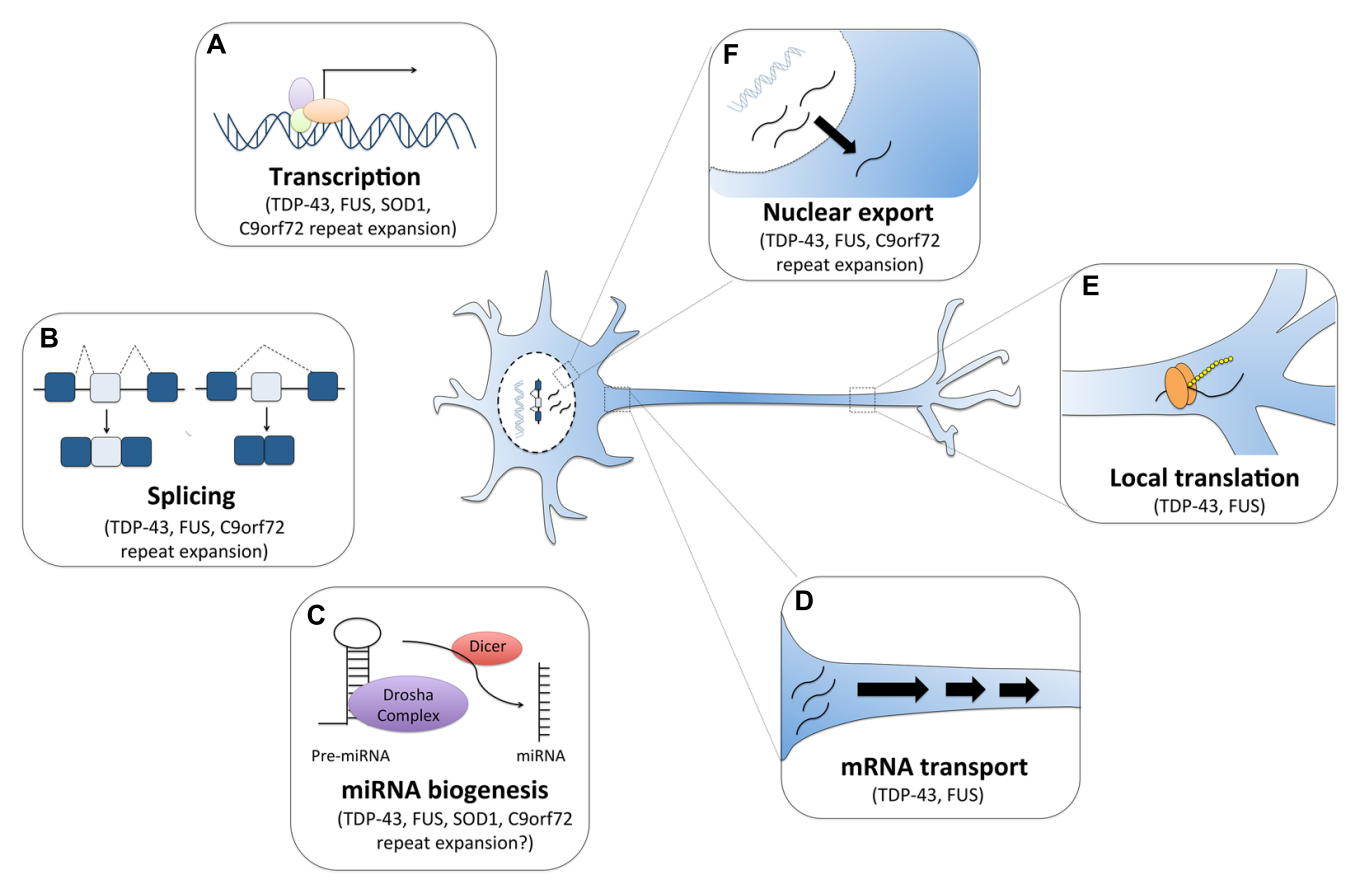

FIGURE 1 | RNA dysfunction in amyotrophic lateral sclerosis (ALS). Major ALS mutations may disrupt RNA processing by several mechanisms. For instance, (A) mutations in ALS genes SOD1, TDP-43, FUS and C9orf72 can alter gene expression. (B) The RNA binding proteins TDP-43 and FUS can affect global splicing machinery. Dipeptide repeat proteins from C9orf72 intronic expansion can also alter splicing patterns of specific RNAs. (C) TDP-43, FUS, and dipeptide proteins can also promote microRNA biogenesis as components of the Drosha and Dicer complexes. TDP-43 and FUS also alter mRNA transport (D) and local translation (E). (F) TDP-43 and FUS predominantly reside in the nucleus, but when mutated they are can mislocalization to the cytoplasm where they bind and regulate different sets of RNAs including the export and mislocalization of other transcripts to the cytoplasm. Poly-PR dipeptide can also bind nuclear pores channels blocking the import and export of molecules.

(NRXN1-3) (Polymenidou et al., 2011), neuroligin (NLGN1-2) (Polymenidou et al., 2011), scaffolding protein Homer2 (Sephton et al., 2011), microtubule-associated protein 1B (MAP1B) (Coyne et al., 2014), GABA receptors subunits (GABRA2, GABRA3) (Narayanan et al., 2013), AMPA receptor subunits (GRIA3, GRIA4) (Sephton et al., 2011; Narayanan et al., 2013), syntaxin 1B (Narayanan et al., 2013), and calcium channel cacophony (Chang et al., 2014). The development of TDP-43 animal models has offered the opportunity to explore synaptic alterations in ALS (Feiguin et al., 2009; Armstrong and Drapeau, 2013; Handley et al., 2017) and continuous efforts are being made to identify compounds that can facilitate synaptic transmission in ALS (Patten et al., 2017). Armstrong and Drapeau (2013) reported that expression of mutant TARDPG348C mRNA in zebrafish resulted in impaired synaptic transmission, reduced frequency of miniature endplate currents (mEPCs) and reduced quantal transmission. Remarkably, they also demonstrated that all these synaptic dysfunction features in their zebrafish TARDBP mutant were stabilized by chronic treatment the L-type calcium channel agonists (Armstrong and Drapeau, 2013). In drosophila neurons, TDP-43 depletion was shown to reduce dendritic branching as well as synaptic formation (Feiguin et al., 2009; Lu Y. et al., 2009). Overexpression or knocking down TDP-43 in cultured mammalian neurons also led to reduced dendritic branching (Herzog et al., 2017). In TDP-43 ${ }^{\mathrm{A} 315 \mathrm{~T}}$ mice, Handley et al. (2017) showed that expression of mutant TDP-43 alters dendritic spine development, spine morphology and neuronal synaptic transmission. Collectively, these independent studies on several model systems, suggest that TDP-43 may play an important role in neuronal morphology, synaptic transmission and neuronal plasticity likely via regulation of RNA processing of various synaptic genes (Godena et al., 2011; Sephton et al., 2011; Colombrita et al., 2012; Narayanan et al., 2013; Chang et al., 2014).

TDP-43 is also known to act as a splicing regulator to reduce its own expression level by binding to the $3^{\prime}$ UTR of its own pre-mRNA (Ayala et al., 2011). Additionally, it functions as a splicing factor whose depletion or overexpression can affect the alternative splicing of specific targets (Polymenidou et al., 2011; Tollervey et al., 2011). Indeed, the alternative splicing of several genes were reported to be altered in human CNS tissues from TDP-43 ALS cases (Shiga et al., 2012; Yang et al., 2014). For instance, the level of the polymerase delta interacting protein 3 (POLDIP3) variant-2 mRNA (lacking exon 3) was significantly increased in the CNS of ALS patients with ALS, while that of variant-1 mRNA remained unchanged (Shiga et al., 2012). This was consistent with findings that TDP-43 directly regulates the inclusion of exon 3 of POLDIP3 and that depletion of TDP-43 in cell culture models increased variant-2 mRNA (Shiga et al., 2012). TDP-43 has also been shown to regulate splicing of the cystic fibrosis transmembrane regulator (CFTR) gene and controls exon skipping by within the pre-mRNA 
(Buratti et al., 2004). Importantly, it controls the alternative splicing of apolipoprotein AII (APOAII) (Mercado et al., 2005) and survival of motor neuron $(S M N)$ transcripts (Bose et al., 2008). Specifically, TDP-43 was shown to enhance the inclusion of exon 7 during the maturation of human SMN2 pre-mRNA, which results to an increase in full-length SMN2 mRNA level in neurons (Bose et al., 2008). Furthermore, recently TDP-43 was shown to bind to HNRNPA1 pre-mRNA to modulate its alternative splicing (Deshaies et al., 2018). TDP-43 depletion resulted in exon7B inclusion, culminating in a longer hnRNAP $\mathrm{A} 1 \mathrm{~B}$ isoform that is aggregation-prone and cytotoxic (Deshaies et al., 2018). Collectively, these studies demonstrated that loss of TDP-43 results to alterations in alternative splicing of many genes and some of which, for example HNRNPA1, can contribute to cellular vulnerability. It would be interesting further to investigate the contribution of the alteration of splicing of these genes (POLDIP3, CFTR, APOAII, SMN2, HNRNPA1) to the pathogenesis of ALS.

TDP-43 is actively transported along axons and co-localizes with other well-known transport RNA binding proteins close to synaptic terminals (Wang I.F. et al., 2008; Narayanan et al., 2013). It was reported that TDP-43 mutations impair mRNA transport function in vivo and in vitro (Alami et al., 2014). In addition to a role in mRNA transport, TDP-43 also acts as a regulator of mRNA stability (Strong et al., 2007; Fiesel and Kahle, 2011). It was shown to directly interacts with the $3^{\prime}$ UTR of neurofilament light chain (NFL) mRNA to stabilize it (Strong et al., 2007) and associates with futsch/MAP1B mRNA in Drosophila to regulates its localization and translation (Coyne et al., 2014). Particularly, TDP-43 was found to interact with 14-3-3 protein subunits to modulate the stability of the NFL mRNA (Volkening et al., 2009). Abnormal regulation of NFL mRNA has been observed in ALS patients (Wong et al., 2000) and disruption of NFL mRNA stoichiometry leads to motor neuron death and symptoms of ALS in animal models (Xu et al., 1993; Julien et al., 1995). It is, thus, very likely that TDP-43 mutations may cause motor neuron degeneration by interfering with RNA processing of NFL mRNA.

Other important identified targets regulated by TDP43 at mRNA level that may play a role in disease are G3BP (McDonald et al., 2011) and TBC1D1 (Stallings et al., 2013). G3BP is an essential component of stress granules, which are cytoplasmic non-membrane organelles that store translationally arrested mRNAs that accumulate during cellular stress (Kedersha and Anderson, 2007). Stress granules consists of polyadenylated mRNAs, translation initiation factors (e.g., eIF3, eIF4E, and eIF4G), small ribosomal subunits and a numerous RNA-binding proteins (Protter and Parker, 2016). TDP-43 is recruited to stress granules in cellular models upon exposure to different stressors (Colombrita et al., 2009; LiuYesucevitz et al., 2010; Bentmann et al., 2012). Importantly, cytosolic TDP-43 mutants are more efficiently recruited to stress granules upon cellular stress compared to nuclear wild-type TDP-43 (Liu-Yesucevitz et al., 2010). Prolonged stress is thought to promote sequestration of TDP-43 and their mRNA targets in stress granules; thereby inhibiting translation and potentially contributing to ALS progression (Ramaswami et al., 2013).

\section{FUSED IN SARCOMA (FUS)}

Mutations in FUS are detected in $4-5 \%$ of familial ALS patients as well as in sporadic ALS (Kwiatkowski et al., 2009; Vance et al., 2009; Corrado et al., 2010; DeJesus-Hernandez et al., 2010). FUS is an RNA/DNA-binding protein of 526 amino acids, consisting of an RNA-recognition motif, a SYGQ (serine, tyrosine, glycine and glutamine)-rich region, several RGG (arginine, glycine and glycine)-repeat regions, a C2C2 zinc finger motif and a nuclear localization signal (NLS) (Iko et al., 2004). C-terminal ALS FUS mutations disrupt the NLS region and the nuclear import of FUS; resulting in cytoplasmic accumulation (Kwiatkowski et al., 2009; Vance et al., 2009).

Similarly to TDP-43, FUS plays multiple roles in RNA processing by directly binding to RNA. Using CLIP-based methods, several groups have identified thousands of RNA targets bound by FUS in various cell lines (Hoell et al., 2011; Colombrita et al., 2012; Ishigaki et al., 2012), and brain tissues (Lagier-Tourenne et al., 2012; Rogelj et al., 2012). Interestingly, FUS was identified in spliceosomal complexes (Rappsilber et al., 2002; Zhou et al., 2002) and interacting with several key splicing factors (such as hnRNP A1, YB-1) (Rapp et al., 2002; Meissner et al., 2003; Kamelgarn et al., 2016) as well as with the U1 snRNP (Yamazaki et al., 2012; Yu et al., 2015). FUS regulates splicing events for neuronal maintenance and survival (Lagier-Tourenne et al., 2012). Given that FUS plays an essential role in splicing regulation, the consequence of its loss of function in ALS on RNA splicing has been immensely investigated (LagierTourenne et al., 2012; Zhou Y. et al., 2013; Reber et al., 2016). For instance, Reber et al. (2016) showed by mass spectrometric analysis that minor spliceosome components are highly enriched among the FUS-interacting proteins. They further reported that FUS interacts with the minor spliceosome and directly regulates the removal of minor introns (Reber et al., 2016). Moreover, the FUS ${ }^{\mathrm{P} 525 \mathrm{~L}}$ ALS mutation, which destroys the NLS and results in cytoplasmic retention of FUS (Dormann et al., 2010), inhibits splicing of minor introns and causes mislocalization of the minor spliceosome components U11 and U12 snRNA to the cytoplasm and inhibits splicing of minor introns (Reber et al., 2016). Loss of function of FUS led to splicing changes in more than 300 genes mice brains (Lagier-Tourenne et al., 2012) and importantly a vast majority minor intron containing mRNAs was altered (Reber et al., 2016). Corroborating the results with mouse brain, many minor intron-containing genes were found to be downregulated in FUS-depleted SH-SY5Y cells (Reber et al., 2016). FUS depletion has been shown to affect minor intron containing genes that are important for neurogenesis (PPP2R2C), dendritic development $(A C T L 6 B)$ and action potential transmission in skeletal muscles (SCN8A and SCN4A) (Reber et al., 2016) and may contribute to ALS pathogenesis. FUS has also been shown to regulate alternative splicing of genes related to cytoskeletal organization, axonal growth and guidance such as the microtubule-associated protein tau (MAPT) (Ishigaki et al., 2012; Orozco et al., 2012; Rogelj et al., 2012), Netrin G1 
(NTNG1) (Rogelj et al., 2012), neuronal cell adhesion molecule (NRCAM) (Rogelj et al., 2012; Nakaya et al., 2013) and the actin-binding LIM (ABLIM1) (Nakaya et al., 2013). For example, FUS knockdown has been shown to promote inclusion of exon 10 in the MAPT/tau protein and to significantly cause shortened axon length and growth cone enlargement (Orozco et al., 2012). Loss of function of FUS altered MAPT/tau isoform expression and likely disturbed cytoskeletal function impairing axonal growth and maintenance. Interestingly, axon retraction and denervation are early events in ALS (Boillee et al., 2006; Nijssen et al., 2017). Disruption of cytoskeleton function may thus play an important role in neurodegeneration in ALS.

Besides its functions in splicing, FUS has been proposed to regulate transcription by RNA polymerase II (RNAP2), RNA polymerase III (RNAP3) or cyclin D1 (Wang X. et al., 2008; Tan and Manley, 2010; Brooke et al., 2011; Schwartz et al., 2012; Tan et al., 2012). For instance, transcriptomic analyses showed that knockdown of FUS results in differential expression several genes (Lagier-Tourenne et al., 2012; Nakaya et al., 2013) including many mRNAs encoding proteins important for neuronal function. Transcriptome changes have also been observed in human motoneurons obtained from FUS mutant induced pluripotent stem cells (IPSCs) (De Santis et al., 2017) and transgenic FUS knockin mice (Scekic-Zahirovic et al., 2016). Alterations in the expression of several genes involved in pathways related to cell adhesion, apoptosis, synaptogenesis and other neurodegenerative diseases were reported in these FUS models (Fujioka et al., 2013; Scekic-Zahirovic et al., 2016; De Santis et al., 2017). Among these genes TAF15, which is mutated in some case of ALS (Couthouis et al., 2011), has been found to be upregulated in several ALS FUS models including human mutant IPSC derived motoneurons (De Santis et al., 2017), FUS knockout and knockin mouse (Kino et al., 2015; Scekic-Zahirovic et al., 2016). However, it remains to be determined whether TAF15 upregulation upon FUS loss- or toxic gain- of function contributes to ALS pathogenesis.

FUS is also incorporated into stress granules under cellular stress conditions (Sama et al., 2013). Sequestration of FUS and its protein partners into these cytoplasmic organelles appears to contribute to ALS pathogenesis (Yasuda et al., 2013). An example of such a protein partner is Pur-alpha, which co-localizes with mutant FUS and becomes trapped in stress granules in stress conditions, as reported in ALS patient cells carrying FUS mutations (Di Salvio et al., 2015; Daigle et al., 2016). It has been shown that FUS physically interacts with Pur-alpha. In vivo expression of Pur-alpha in Drosophila significantly exacerbates the neurodegeneration caused by mutated FUS. Conversely, Di Salvio et al. (2015) showed that the downregulation of Pur-alpha in neurons expressing mutated FUS significantly improves fly climbing activity. It was subsequently demonstrated that overexpression Pur-alpha inhibits cytoplasmic mislocalization of mutant FUS and promotes neuroprotection (Daigle et al., 2016). However, the function of Pur-alpha in regulating ALS pathogenesis remains elusive.

\section{SUPEROXIDE DISMUTASE-1 (SOD1)}

Unlike TDP43 and FUS, SOD1 does not contain RNA-binding motifs, however, several reports have demonstrated a potential role of mutant SOD1 in regulating RNA metabolism (Menzies et al., 2002; Lu et al., 2007; Lu L. et al., 2009; Chen et al., 2014). Particularly, mutant SOD1 can bind mRNA species such as vascular endothelial growth factor (VEGF) and NFL and negatively affects their expression, stabilization and function (Menzies et al., 2002; Lu et al., 2007; Lu L. et al., 2009; Chen et al., 2014). More precisely, mutant SOD1 can directly bind to specific adenylate- and uridylate-rich stability elements (AREs) located in the $3^{\prime}$ UTR of transcripts of VEGF (Lu et al., 2007) and NFL (Chen et al., 2014). It is believed that such a gain of abnormal protein-RNA interactions can be caused by SOD1 misfolding that results in the exposure of polypeptide portions with the ability to bind nucleic acids (Kenan et al., 1991; Tiwari et al., 2005).

Binding of mutant SOD1 to the $3^{\prime}$ UTR of the VEGF mRNA results in the sequestration of other ribonucleoproteins such as TIAR and HuR into insoluble aggregates. These interactions, which are specific to mutant SOD1, result in decline levels of VEGF mRNA, impairment of HuR function and ultimately hampering their neuroprotective actions during stress responses (Lu et al., 2007; Lu L. et al., 2009).

In motor neuron-like NSC34 cell lines expressing mutant SOD1 (G37R or G93A), the level of NFL mRNA is significantly reduced (Menzies et al., 2002). Reduction in NFL mRNA levels has also been reported in G93A transgenic mice and human spinal motor neurons from SOD1-ALS cases (Menzies et al., 2002). It is proposed that destabilization NFL mRNA by mutant SOD1, result to altered stoichiometry of neurofilament (NF) subunits and subsequent NF aggregation in motor neurons (Chen et al., 2014). NF inclusion in the soma and proximal axons of spinal motor neurons is a hallmark of ALS pathology (Hirano et al., 1984). In IPSC-derived model of ALS, a reduction of NFL mRNA level has been reported to result in NF aggregation and neurite degeneration (Chen et al., 2014). Altogether, these studies support a pathogenic role for dysregulation of RNA processing in SOD1-related ALS.

Interestingly, SOD1 has been shown to interact with TDP-43 to modulate NFL mRNA stability (Volkening et al., 2009). As mentioned above, TDP-43 was found to directly interact with the 3' UTR of NFL mRNA to stabilize it (Strong et al., 2007). Altogether, these studies suggest that SOD1 and TDP-43 may act in a possible common action in regulating specific RNA stability. In the case of NFL mRNA, it would be interesting to investigate whether mutant SOD1 dislodges TDP-43 from the NFL mRNA in a manner that would affect its mRNA metabolism and potentially making NF prone to form aggregates.

Furthermore, there have been several transcriptome investigations in SOD1 human samples (D'Erchia et al., 2017), motor neuron-like NSC34 cell culture model (Kirby et al., 2005) and transgenic animals including mice (Lincecum et al., 2010; Bandyopadhyay et al., 2013; Sun et al., 2015), rat (Hedlund et al., 2010) and drosophila (Kumimoto et al., 2013). These studies have reported dysregulation of genes involved 
in pathways related to the neuroinflammatory and immune response, oxidative stress, mitochondria, lipid metabolism, synapse and neurodevelopment (Hedlund et al., 2010; Lincecum et al., 2010; Bandyopadhyay et al., 2013; Kumimoto et al., 2013; Sun et al., 2015; D’Erchia et al., 2017). However, in these studies it is not clear whether SOD1 directly or indirectly impact the regulation of the differentially expressed genes. In a recent elegant study, Rotem et al. (2017), compared transcriptome changes in SOD1 and TDP-43 models. They found that most genes that were altered in the SOD1 ${ }^{\mathrm{G} 93 \mathrm{~A}}$ model were not dysregulated in the TDP- $43^{\mathrm{A} 315 \mathrm{~T}}$ model, and vice versa (Rotem et al., 2017). There were, however, a few genes whose expressions were altered in both ALS models (Rotem et al., 2017). These findings are consistent with the ALS pathology, which is distinguishable between the ALS-related SOD1 phenotype and the TDP-43 phenotype. Although different cellular pathways are likely activated by SOD1 versus TDP-43, it is very plausible that they ultimately convergence onto common targets to result in similar motor neuron toxicity and ALS phenotype.

\section{C9orf72 INTRONIC EXPANSION}

In 2011, a large GGGGCC hexanucleotide repeat expansion in the first intron or promoter region of the C9orf 72 gene has been discovered as a new cause of ALS (DeJesus-Hernandez et al., 2011; Renton et al., 2011). C9orf72 repeat expansion mutations account for about $50 \%$ of familial ALS and $5-10 \%$ of sporadic ALS (Majounie et al., 2012). It remains a topic of debate whether the repeat expansion in C9orf 72 causes neurodegeneration primarily through a toxic gain of function, loss of function, or both. The C9orf72 repeat expansion is transcribed in both the sense and antisense directions and leads to accumulations of repeatcontaining RNA foci in patient tissues (Gendron et al., 2013). The formation of RNA foci facilitates the recruitment of RNAbinding proteins, causes their mislocalization and interferes with their normal functions (Simon-Sanchez et al., 2012; Donnelly et al., 2013; Lee et al., 2013; Gitler and Tsuiji, 2016). Indeed, RNA foci may bind RNA binding proteins and alter RNA metabolism (Donnelly et al., 2013; Lee et al., 2013; Mori et al., 2013a). For example, Mori et al. (2013a) and Hutvagner et al. (2001) showed that RNA foci can sequester hnRNP-A3 and repress its RNA processing function. Aborted transcripts containing the repeat can also disrupt nucleolar function (Haeusler et al., 2014). Importantly, these foci can sequester nuclear proteins such as TDP-43 and FUS, impacting expression of the their RNA targets and culminating in a range of RNA misprocessing events. Other RNA binding proteins binding to RNA foci include hnRNP A1, hnRNP-H, ADARB2, Pur- $\alpha$, ASF/SF2, ALYREF and nucleolin (Donnelly et al., 2013; Lee et al., 2013; Sareen et al., 2013; Xu et al., 2013; Cooper-Knock et al., 2014; Haeusler et al., 2014). Antisense oligonucleotides (ASOs) targeting the C9orf72 repeat expansion suppress RNA foci formation, attenuate sequestration of specific RNA-binding proteins and reverse gene expression alterations in C9orf72 ALS motor neurons derived from IPSCs (Donnelly et al., 2013; Lagier-Tourenne et al., 2013).
Additionally, simple dipeptide repeats (poly-GA, poly-GP, poly-GR, poly-PA, and poly-PR) can be generated by repeatassociated non-ATG-dependent (RAN) translation of both the sense and antisense strands that have a variety of toxic effects (Ash et al., 2013; Mori et al., 2013b). Poly-PR and poly-GR can alter the splicing patterns of specific RNAs. For example, poly-PR has been shown to cause exon-skipping in RAN and PTX3 RNA (Kwon et al., 2014). Dipeptides repeat proteins have also been found to be toxic by creating aggregates sequestrating cytoplasmic proteins (Freibaum and Taylor, 2017). Poly-GR dipeptide co-localizes with several ribosomal subunits and with a transcription factor elF3 $\eta$ (Zhang et al., 2018c). This suggests a ribosomal dysfunction, which implies a defect in RNA translation. In line with these findings, a recent report demonstrated that poly-PR co-localizes with the nucleolar protein, nucleophosmin, and reduces the expression of several ribosomal RNA (Suzuki et al., 2018). Suzuki et al. (2018) further showed that the reduction in the expression of ribosomal RNA results in neuronal cell death and this could be rescued by overexpression of an accelerator of ribosome biogenesis, Myc (Suzuki et al., 2018). RNA sequencing reveals that more than 6,000 genes are up or down regulated in mice that express the dipeptide construct in the brain (Zhang et al., 2018c). Other findings show that poly-PR dipeptide binds nuclear pores channels blocking the import and export of molecules. The dipeptide actually binds the nucleoporin proteins Nup54 and Nup98 that rim the central channel of the pore (Shi et al., 2017). The accumulation of poly-PR dipeptide at the nuclear pore was found to correlate with defect in nuclear transport of RNA and protein, which is consistent with previous findings (Freibaum et al., 2015; Zhang et al., 2015).

The last proposed mechanism involved in ALS pathogenesis is a haploinsufficiency due to the expansion of repetition leading to a decreased transcription of the gene and consequently to a decrease of its translation (Ciura et al., 2013). Studies have demonstrated that C9orf72 expansion repeat can interfere with transcription or splicing of C9orf 72 transcripts (Mori et al., 2013b; Haeusler et al., 2014; Highley et al., 2014). It has also been proposed that the C9orf72 expansion repeat could disrupt the C9orf72 promoter activity thereby reducing its expression (Gijselinck et al., 2016). Several studies have demonstrated alterations in the C9orf72 ALS transcriptome (Donnelly et al., 2013; Prudencio et al., 2015; Selvaraj et al., 2018). Interestingly, a recent article reported an increased expression of the calciumpermeable GluA1 AMPA receptor subunit in motoneurons derived from IPSC of patients with C9orf72 mutations (Selvaraj et al., 2018). This alteration in AMPA receptor composition led to an enhanced motoneuron vulnerability to AMPA-induced excitotoxicity (Selvaraj et al., 2018). It remains to be determined whether the increased expression of GluA1 AMPA subunit is related to reduced levels of C9orf72, RNA foci and/or dipeptide repeats.

C9orf72 has also been showed to be involved in the generation of stress granules (Maharjan et al., 2017) and sequestering other RNA binding proteins that are involved in nucleo-cytoplasmic transport (Zhang et al., 2015, 2018b). It has been found that stress granules observed in C9orf72 mutants co-localizes with Ran GAP (Zhang et al., 2015, 2018b); which is known to activate 
Ran GTPase. This GTPase in involved in nucleo-cytoplasmic transport. It has also been published that expressing Ran GAP rescues the age-related motor defects in flies expressing the GGGGCC repeats (Zhang et al., 2018a). Very recently, it has also been reported that one of the dipeptide generated by the expansion has a role in formation of these stress granules (Zhang et al., 2018c). Moreover, importins and exportins are sequestered in stress granules; which also implies that protein transport in altered (Zhang et al., 2018b).

These toxic gain- or loss-of function mechanisms are thought to be all involved in synergy in ALS pathogenesis and it can be summed up that that altered RNA processing plays a key role in C9orf72-mediated toxicity through two ways. The first is altered processing of the expanded C9orf72 transcript itself, in terms of altered transcription, splicing defects, nuclear aggregation and non-conventional translation (Barker et al., 2017). The second involves downstream and indirect changes in RNA processing of other transcripts. A thorough understanding of RNA metabolism dysregulation could definitely bring a major enlightenment on how C9orf72 mutation leads to ALS and provide insights on therapeutic targets.

\section{DYSREGULATION OF MICRORNA (miRNA) IN ALS}

Multiple mechanisms control the proper levels of RNA and subsequent protein expression; among these are microRNAs (miRNAs) (Catalanotto et al., 2016). They are endogenous small non-coding RNAs (approximately 22 nucleotides in length) that are initially transcribed by the RNA polymerase II as primary miRNA (pri-miRNAs) transcripts. These primiRNAs are processed into precursor miRNAs (pre-miRNAs) by the nuclear ribonuclease III (RNase III), DROSHA, and the double-stranded RNA-binding protein, DGCR8, which anchors DROSHA to the pri-miRNA transcript (Lee et al., 2003; Denli et al., 2004). Pre-miRNA is then exported into the cytoplasm by exportin-5 (Yi et al., 2003), where it is processed into a mature miRNA by the DICER enzyme (Hutvagner et al., 2001; Ketting et al., 2001). The mature miRNA is then incorporated with a ribonucleoprotein (RNP) complex with argonaute (AGO) proteins to form the RNA-induced silencing complex (RISC) (Hammond et al., 2001; Schwarz et al., 2003; Kawamata and Tomari, 2010), which mediates inhibition of translation and/or mRNA degradation of targeted transcripts that are complementary to the miRNA (Hutvagner and Zamore, 2002; Yekta et al., 2004). The recognition of mRNAs by miRNAs occurs through base-pairing interactions within the $3^{\prime}$-untranslated region (UTR) of the targeted mRNAs. Besides their well-known gene silencing functions, miRNAs can also induce up-regulation of their targets (Vasudevan et al., 2007; Lin et al., 2011; Truesdell et al., 2012; Vasudevan, 2012).

MiRNAs play important roles in several biological processes such as cell proliferation (Chen et al., 2006), cell differentiation (Naguibneva et al., 2006), apoptosis (Matsushima et al., 2011), and patterning of the nervous system (Johnston and Hobert, 2003). Interestingly, several miRNAs have been particularly shown to be essential for motor neuron development and survival (see review, Haramati et al., 2010). For example, in developing chick, it was demonstrated that the activation of the miRNA miR9 is necessary to suppress the expression of the transcription factor onecut1, which in turn helps to drive differentiation of neural progenitor cells into spinal motor neurons (Luxenhofer et al., 2014). It is believed that several miRNAs work in concert to establish motor neuron identity. Indeed, in addition to miR9, other miRNAs such as miR128 (Thiebes et al., 2015), miR-196 (Asli and Kessel, 2010), miR-375 (Bhinge et al., 2016) have been shown to play a role in motor neuron differentiation and localization. Loss of DICER function within progenitor cells results in aberrant motor neuron development while its loss in motor neuron leads to progressive motor neuron degeneration (Haramati et al., 2010; Chen and Wichterle, 2012). Furthermore, miRNAs are important players for NMJ function, synaptic plasticity and for maintaining cytoskeletal integrity (see review, Hawley et al., 2017).

The ALS genes, TDP-43 and FUS, were identified in a protein complex with RNAse III DORSHA and shown to play a role in miRNA biogenesis (Freibaum et al., 2010; Da Cruz and Cleveland, 2011). TDP-43, in particular was shown to associate with proteins involved in the cytoplasmic cleavage of pre-miRNA mediated by the DICER enzyme (Freibaum et al., 2010). It is thus to no surprise that dysregulation of miRNAs has been observed in ALS (Li et al., 2013; Zhang et al., 2013; Dini Modigliani et al., 2014; Eitan and Hornstein, 2016). Indeed, mutations in TARDBP result in differential expression of miRNAs - miR-9, miR132, miR-143, and miR-558 (Kawahara and Mieda-Sato, 2012; Zhang et al., 2013). Interestingly, the expression of several of these miRNAs (miR-9, miR-132, miR-143) and including others (such as miR-125, miR-192) are altered upon FUS depletion (Morlando et al., 2012). MiR-9 expression is also found to be upregulation in mutant SOD1 mice (Zhou F. et al., 2013). These dysregulated miRNAs are essential for motor neuron development and maintenance (Otaegi et al., 2011; Luxenhofer et al., 2014), axonal growth (Dajas-Bailador et al., 2012; Kawahara and Mieda-Sato, 2012) and synaptic transmission (Edbauer et al., 2010; Sun et al., 2012). Thus, these miRNA alterations likely contribute to the pathological phenotype observed in ALS.

Additionally, depletion of TDP-43 in cell culture systems has also been shown to change the total miRNA expression profile (Buratti et al., 2010). A similar observation was recently observed in motoneurons progenitors derived from human ALS IPSCs (Rizzuti et al., 2018). Particularly, it was reported that 15 miRNAs were dysregulated including disease-relevant miR-34a and miR504, which are known to be, implicated synaptic vesicle regulation and cell survival (Rizzuti et al., 2018). Additionally, another important miRNA, namely microRNA-1825, was found to be downregulated in CNS of both sporadic and familial ALS patients (Helferich et al., 2018). Interestingly, reduced levels of microRNA1825 was demonstrated to cause a translational upregulation of tubulin-folding cofactor b $(T B C B)$ which consequently to depolymerization and degradation of tubulin alpha-4A (TUBA4A), which is encoded by a known ALS gene (Helferich et al., 2018). 


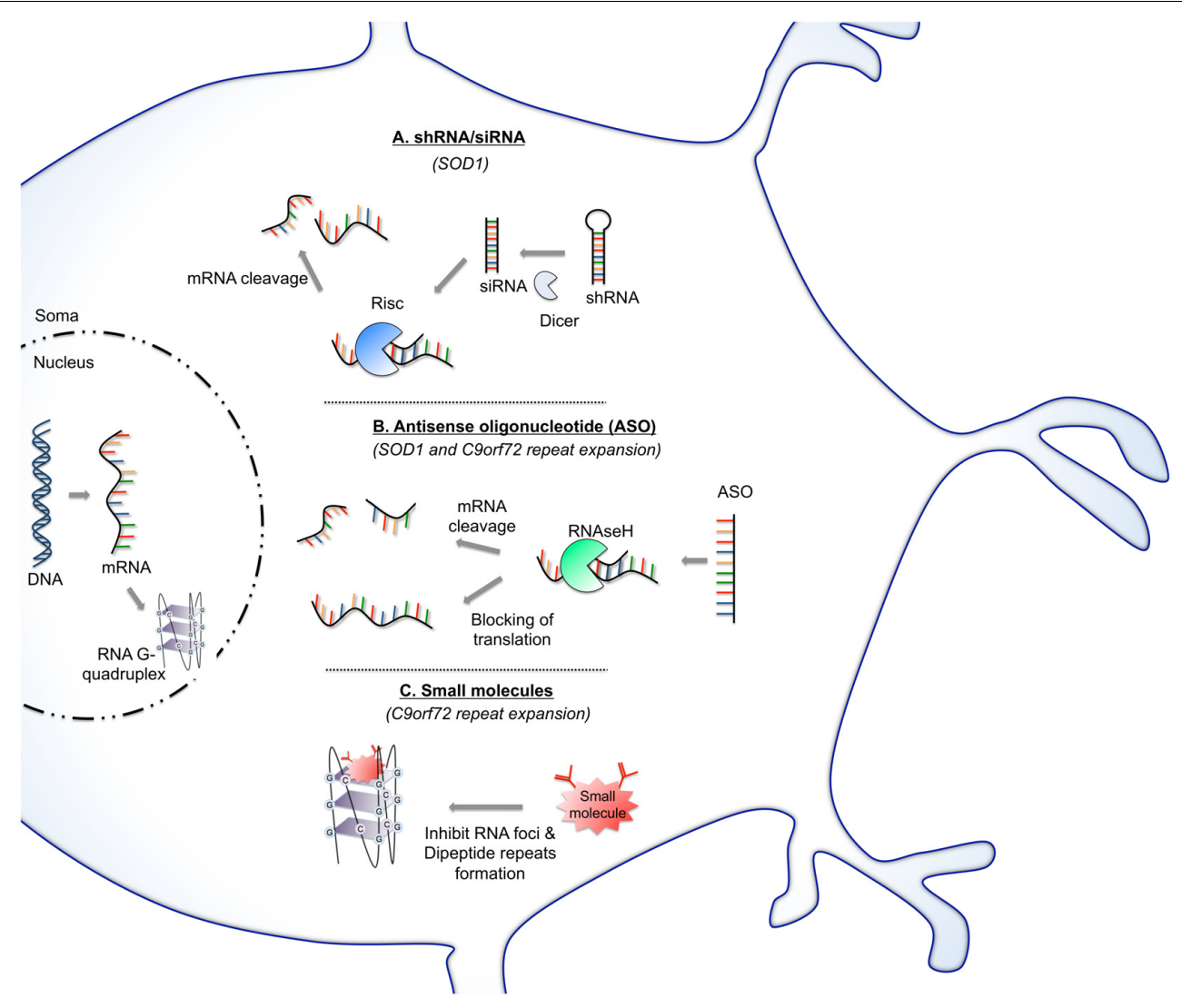

FIGURE 2 | RNA-based therapy approaches for potentially treating ALS. (A) SiRNAs operate through RNA interference pathway. After strand unwinding, one siRNA strand binds argonaute proteins as part of the RNA-induced silencing complex (RISC) and is recruited to a target mRNA which is then cleaved. Virus can provide a means of shRNA, which will be cleaved once in the cytoplasm by dicer enzyme into siRNA. This approach has been evaluated to reduce the level of mutant SOD1 protein. (B) Antisense oligonucleotide (ASO) binds to targeted mRNA and induces its degradation by endogenous RNase $\mathrm{H}$ or blocks the mRNA translation. This strategy is being exploited as a potential therapeutic avenue in ALS aiming principally to reduce the protein level of SOD1 protein or by targeting of C9orf72 RNA foci. (C) Small molecules can be designed to target and stabilize RNA structures. This approach was particularly tested to stabilize G-quadruplex of C9orf72 GGGGCC repeat RNA. Stabilization of G-quadruplex structure reduces RNA foci formation and blocks repeat translation.

In several repeats diseases such as myotonic dystrophy, fragile $\mathrm{X}$ tremor and ataxia syndrome, toxic RNA from expansion repeats cause widespread RNA splicing abnormalities, degeneration of affected tissues (Miller et al., 2000) and alter miRNA processing (Sellier et al., 2013). Since its discovery, C9orf72 GGGGCC expansion repeat was also questioned as a disruptor of miRNA processing. Recently, the DROSHA protein was found to be mislocalized in dipeptide repeat protein-aggregates in frontal cortex and cerebellum C9orf72 ALS/FTLD patients (Porta et al., 2015). An involvement of the miRNA pathway in motor neuron impairment in ALS is evident and further investigations on miRNAs dysregulation in ALS pathogenesis could eventually lead to the identification of therapeutic targets.

\section{RNA-TARGETED THERAPEUTICS FOR ALS}

Our understanding of RNA biology has expanded tremendously over the past decades, resulting in new approaches to engage
RNA as a therapeutic target. More precisely, RNA-targeted therapeutics have been developed to mediate the reduction or expression of a given target RNA by employing mechanisms such as RNA cleaving, modulation of RNA splicing, inhibition of mRNA translation into protein, inhibition of miRNA binding sites, increasing translation by targeting upstream open reading frames and disruption of RNA structures regulating RNA stability (Robertson et al., 2010; Fellmann and Lowe, 2014; Vickers and Crooke, 2014; Havens and Hastings, 2016; Liang et al., 2016). Therapeutics that directly target RNAs are promising for a broad spectrum of disorders, including the neurodegenerative diseases (Scoles and Pulst, 2018) and are currently under evaluation as potential strategies for treating ALS. The RNA therapeutics approaches include RNA interference (RNAi) and ASOs (Figure 2), both bind to their target nucleic acid via Watson-Crick base pairing and cause degradation of or inactivate the targeted mRNA (Burnett and Rossi, 2012). Recently, application of innovative drug discovery approaches has showed that targeting RNA with bioactive small molecules is achievable (Disney, 2013; Bernat and Disney, 2015). A few researchers 
including us are currently exploiting such a new type of RNAtargeted therapeutics to search for RNA-targeted small molecules as C9orf72 ALS therapeutics.

\section{RNA Interference (RNAi)}

RNAi is an endogenous cellular mechanism to regulate mRNA. It operates sequence specifically and post-transcriptionally via the RISC (Carthew and Sontheimer, 2009). Methods of mediating the RNAi effects are via small interfering RNA (siRNA), short hairpin RNA (shRNA), and artificial miRNA (Fire et al., 1998; Moore et al., 2010; Chakraborty et al., 2017). These approaches can help to reduce the expression of mutant (toxic) gene and can provide significant therapeutic benefit in treating ALS and other neurodegenerative disease implicating aberrant accumulation of misfolded proteins.

The challenge of using siRNA for treating ALS is that it has to be designed to have the specificity and ability to reduce the aberrant mutant protein while leaving wild-type protein intact. Attempts were made to design siRNA, which could recognize just a single nucleotide alternation to selectively suppress mutant SOD1 (particularly G93A) expression leaving wild-type SOD1 intact (Yokota et al., 2004; Wang H. et al., 2008). The design of siRNA G93A.1 and G93A.2 by Yokota et al. (2004) were found to successfully suppress the expression of approximately $90 \%$ of mutant SOD1 G93A. Importantly, both siRNA had virtually little or no effect on wild-type SOD1 expression (Yokota et al., 2004). To achieve long-term expression of siRNA in cells, the use of viral delivery system has proved powerful to provide a continuous delivery and expression of shRNA in sufficient quantities (Bowers et al., 2011). Indeed, diverse viral vectors have been studied such as adeno-associated virus (AAV), lentivirus (LV), and rabies-glycoprotein-pseudotyped lentivirus (RGP-LV) (Raoul et al., 2005; Wu et al., 2009). Recombinant AAVs are currently the choice of RNAi treatment vehicle for neurological diseases because they are non-pathogenic and safe (Maguire et al., 2014; Smith and Agbandje-McKenna, 2018). Several studies have aimed at engineering AAV serotypes with better cell-type and tissue specificities and an improved immune-evasion potential (Gao et al., 2005; Weinmann and Grimm, 2017). AAV9 and AAVrh10 serotypes have been shown to cross the blood-brain barrier and efficiently transduce cells in the CNS, with widespread and sustained transgene expression in the spinal cord and brain even after just a single injection (Thomsen et al., 2014; Dirren et al., 2015; Borel et al., 2016). Importantly, they can efficiently target neurons and astrocytes, making them the most applicable delivery systems for treating ALS.

Several researchers have independently use siRNA or shRNA to silence mutant SOD1 expression in vitro and in vivo (Miller et al., 2005; Raoul et al., 2005; Ralph et al., 2005; Foust et al., 2013). Intramuscular delivery of siRNA targeting mutant SOD1 in $S O D 1^{\mathrm{G} 93 A}$ mice delays the onset of motor neuron symptoms and extend their survival (Miller et al., 2005). Similarly, SOD1 $1^{\mathrm{G} 93 \mathrm{~A}}$ mice treated with injection of AAV encoding shRNA against human SOD1 mRNA (hSOD1) exhibited delayed diseases onset and significantly increased their survival by $23 \%$ (Foust et al., 2013). The same group later demonstrated the efficacy of this approach in $S O D 1^{\mathrm{G} 93 \mathrm{~A}}$ rats, showing that silencing of $\mathrm{hSOD1}$ expression selectively in the motor cortex also delayed disease onset and prolonged survival (Thomsen et al., 2014). Silencing of SOD1 using an artificial miRNA (miR-SOD1) systemically delivered using the viral vector AAVrh10 in SOD1 ${ }^{\mathrm{G} 93 \mathrm{~A}}$ mice was also found to significantly delayed disease onset, preserved muscle motor functions and extended survival (Borel et al., 2016). Interestingly, similar findings were observed in nonhuman primates treated with AAVrh10-miR-SOD1 (Wang et al., 2014; Borel et al., 2016). These findings suggest that miRNA silencing strategy warrants further investigations and may offer promise for the development for the treatment of SOD1-related ALS.

\section{Antisense Oligonucleotides (ASOs)}

The concept of ASOs was first introduced in 1978, when Stephenson and Zamecnik used a chemically modified oligonucleotide, designed to bind to its complementary sequence in a Rous sarcoma virus transcript to inhibit its gene expression and viral replication (Stephenson and Zamecnik, 1978). ASOs are synthetic single-stranded oligonucleotides that activate the RNAse $\mathrm{H}$, an endonuclease in the nucleus, to degrade the complementary mRNA. They can be designed to specifically target mutant RNAs or mRNA splicing (Bennett and Swayze, 2010). An ASO therapy based (nusinersen) approach designed to promote exon skipping has proven to be very effective in treating spinal muscular atrophy (SMA) in clinical trials (Chiriboga et al., 2016; Finkel et al., 2016; Mendell et al., 2017; Scoto et al., 2017). In late 2016, this antisense drug (marketed as Spinraza) has received FDA approval for the treatment of SMA. This was the first exciting success of ASO therapeutics in neurodegeneration and a significant milestone for ASO therapy, in general. With increased understanding of gain- and loss-of-function mechanisms of genetic forms of ALS, ASOs therapies have also been tested principally tested in SOD1 and C9ORF72 models to target the mutant forms of RNA but not the wild-type.

The first study using an ASO to target SOD1 showed an effective silencing of SOD1 and reduced mutated SOD1 protein throughout the brain and spinal cord of SOD $1^{\mathrm{G} 93 \mathrm{~A}}$ rats (Smith et al., 2006). Infusion of ASOs complementary to hSOD1 mRNA extended survival in SOD $1^{\mathrm{G} 93 \mathrm{~A}}$ rats (Smith et al., 2006). Given these promising preclinical results, the ASO IONIS-SOD1 $1_{\mathrm{Rx}}$ (ISIS 333611 and BIIB067) has been proposed as a therapeutic strategy for SOD1-link ALS and has been clinical tested. In a phase I testing, intrathecal administration of the ASO IONIS-SOD1 $1_{\mathrm{Rx}}$ was showed to be both practical and safe in SOD1 ALS patients (Miller et al., 2013). A phase Ib/IIa trial (NCT02623699) is currently underway to further evaluate safety, tolerability, and pharmacokinetics of IONIS-SOD $1_{\mathrm{Rx}}$. Altogether, the preclinical and clinical tests suggest that ASOs delivered to the CNS represent a feasible treatment for SOD1-related ALS and are safe, however, ASOs are not specific for mutant over wild-type SOD1 and the long-term effects of the reduction of SOD1 need further investigation.

In addition, silencing of SOD1 can be induced by exon skipping of hSOD1 using ASOs complementary to splicing regulatory elements on the primary transcript (Biferi et al., 2017). For instance, administrating an exon-2-targeted ASO 
embedded in a modified U7 small-nuclear RNA and delivered by AAV10, in either newborn or adult (P50) SOD1 ${ }^{\mathrm{G} 93 \mathrm{~A}}$ mice, was shown to increase survival and restore neuromuscular function (Biferi et al., 2017). These recent findings provide new hope for treatment of ALS and open perspectives for a clinical development.

Strong evidence supports that the mechanism by which the GGGGCC repeat expansion in C9orf72 causes the diseases is by toxicity of RNAs that they generate. Thus early development of ASO-based therapeutics for C9orf72 ALS focused on reducing gain-of-function toxicity associated with the repeat expansion. Testing of the efficacy of ASO-based therapeutics for C9orf72 was initially performed on clinically relevant human IPSC-derived neurons and fibroblasts (Donnelly et al., 2013; Lagier-Tourenne et al., 2013; Sareen et al., 2013). More recently, ASOs were also evaluated in mouse models expressing the expanded C9orf72 (O’Rourke et al., 2015; Jiang et al., 2016).

Antisense oligonucleotides were designed to bind within the GGGGCC repeat expansion or within surrounding N-terminal regions of the C9orf72 mRNA transcript to either degrade the transcript or block the interaction between the repeat expansion and RNA-binding proteins (Donnelly et al., 2013). ASOs effectively reduced RNA foci formation, dipeptide proteins, increased survival from glutamate excitotoxicity and restored normal gene expression markers (Donnelly et al., 2013; LagierTourenne et al., 2013; Sareen et al., 2013; O'Rourke et al., 2015; Jiang et al., 2016). These promising findings suggest that ASObased therapy can be a powerful way for treating C9orf72 ALS. They also provided the basis for the initiation of the first C9orf72 ASO clinical trial that is anticipated to start by the end of 2018 .

These planned ASOs trials in ALS as well as ongoing trials of ASOs in SMA, Huntington's disease and Alzheimer's disease will enhance our understanding of this therapeutic approach. Importantly, positive outcomes from these clinical trials will revolutionize the treatment of genetically mediated neurodegenerative diseases.

\section{Small Molecules Targeting RNA}

RNAs adopt discrete secondary and tertiary structures and have pivotal roles in biology and diseases (Bernat and Disney, 2015). The ALS-associated C9orf72 GGGGCC repeat RNA can stably fold to into a four-stranded structure formed by the stacking of planar tetrads of four guanosine residues, termed G-quadruplex (Huppert, 2008; Fratta et al., 2012). This G-quadruplex structure can affect various RNA processing including splicing and translation (Simone et al., 2015). In particular, the C9or72 repeat RNA G-quadruplexes have been shown to specifically sequester RNA-binding proteins and have toxic functions (Haeusler et al., 2016). GGGGCC repeat RNA sequence can also adopt a hairpin structure in addition to G-quadruplexes (Haeusler et al., 2014; Su et al., 2014). Hairpin is composed of a base-paired stem and a loop and it can affect transcription and alternative splicing (Kuznetsov et al., 2008). Targeting these RNA structures of the C9or72 repeat is a potential therapeutic strategy.

Recent developments in technologies and approaches have made the long sought-after goal of developing small-molecule drugs that target RNA possible (Disney, 2013; Bernat and Disney,
2015; Connelly et al., 2016). Small molecules binding to RNA hairpin or G-quadruplex structure have been identified (Di Antonio et al., 2012; Su et al., 2014). This has provided the springboard to initiate the search for small molecules that can specifically target C9orf72 repeat RNA and hinder pathogenic interactions with RNA-binding proteins and/or by interfering with RAN translation (Su et al., 2014; Simone et al., 2018) (Figure 2C).

Su et al. (2014) showed that (GGGGCC) 8 RNA can adopt a hairpin structure in equilibrium with a quadruplex structure. They designed three compounds targeting mainly the hairpin structure of the (GGGGCC) $)_{n}$ RNA and showed that the bioactive small molecule 1a significantly inhibited RAN translation and foci formation in cultured cells (GGGGCC) 66 repeat expansion and in patient-derived neurons (Su et al., 2014). However, these small molecules were only tested in vitro on cellular models. Recently, a drug screen study to identify compounds that specifically target the C9orf72 RNA G-quadruplex structure led to the identification of three lead compounds (Simone et al., 2018). These compounds were then functionally validated as ALS therapeutics in C9orf72 IPSC-derived neurons and C9orf72 repeat-expressing fruit flies. Interestingly, two of the lead compounds reduced RNA foci formation and the levels of toxic dipeptide repeat proteins in IPSC-derived spinal motor neurons and cortical neurons (Simone et al., 2018). The most effective small molecule (DB1273) was then tested in vivo on C9orf72 repeat-expressing fruit flies and was found to significantly reduce dipeptide repeats levels. Furthermore, D1273 improved the survival of the fruit flies (Simone et al., 2018). These studies support the further development of small molecules that selectively bind GGGGCC RNA as a therapeutic strategy for C9orf72 ALS and FTLD.

\section{LIMITATIONS OF RNA-TARGETED THERAPEUTIC STRATEGIES}

RNA-targeted therapeutic approaches offer a treatment strategy with greater specificity, improved potency, and decreased toxicity compared to the small molecules against traditional drug targets (signaling proteins). They represent an important way to treat ALS and other neurodegenerative diseases that need to be considered in the near future. However, there are still some concerns and challenges to overcome for ALS therapeutic applications.

Off-target effects RNAi and ASO remain an important consideration though thorough toxicological and safety research prior to clinical application can diminish some of this concern. The negative charge of siRNA and ASO as well as their size makes it difficult for them to cross the cell membrane. Viral packing is currently widely used to deliver ASO and siRNA into cells. Although, viral vectors are highly efficient as transfer vehicles, immunogenicity of the viral vectors is a major concern. Various other delivery strategies such as nanoparticles, liposomes and aptamers could be more effective and safe. Efforts are also underway to chemically stabilize siRNA, which will avoid the need for viral vectors (Castanotto and Rossi, 2009). 
RNA foci and dipeptide products are generated from both sense and antisense directions of the C9orf72 transcript. However, ASOs for C9orf72 ALS preferentially target sense strand transcripts. There may be a need to design ASO strategies to target toxic RNA transcribed from both directions in order to adequately treat the C9orf72 ALS (Schoch and Miller, 2017). Furthermore, ASO-based therapeutic strategy for C9orf72 ALS only target gain-of-function mechanisms, but loss-of-function mechanisms may also act in synergy to cause pathogenesis in C9orf72 ALS. It is very plausible that an integrated therapeutic approach to inhibit toxic RNA foci/dipeptide repeat protein formation and restore normal levels of C9orf72 may be necessary to fully address the cellular deficits in C9orf72 ALS.

\section{CONCLUSION}

TDP-43, SOD1, FUS, and C9orf72 mutations are involved at various aspects of RNA processing and many of which are shared. It is becoming clear that impaired RNA regulation and processing is a central feature ALS pathogenesis. Given that defects at multiple steps of RNA processing impair cellular function and survival, RNA metabolism can be considered an essential target for therapeutic intervention for ALS and other neurodegenerative disease such as FTLD. The application of RNA-based therapies

\section{REFERENCES}

Abe, K., Itoyama, Y., Sobue, G., Tsuji, S., Aoki, M., Doyu, M., et al. (2014). Confirmatory double-blind, parallel-group, placebo-controlled study of efficacy and safety of edaravone (MCI-186) in amyotrophic lateral sclerosis patients. Amyotroph. Lateral Scler. Frontotemporal Degener. 15, 610-617. doi: 10.3109/ 21678421.2014.959024

Alami, N. H., Smith, R. B., Carrasco, M. A., Williams, L. A., Winborn, C. S., Han, S. S. W., et al. (2014). Axonal transport of TDP-43 mRNA granules is impaired by ALS-causing mutations. Neuron 81, 536-543. doi: 10.1016/j.neuron.2013.12.018

Alarcon, C. R., Goodarzi, H., Lee, H., Liu, X., Tavazoie, S., and Tavazoie, S. F. (2015). HNRNPA2B1 is a mediator of $\mathrm{m}(6) \mathrm{A}$-dependent nuclear RNA processing events. Cell 162, 1299-1308. doi: 10.1016/j.cell.2015.08.011

Armstrong, G. A., and Drapeau, P. (2013). Calcium channel agonists protect against neuromuscular dysfunction in a genetic model of TDP-43 mutation in ALS. J. Neurosci. 33, 1741-1752. doi: 10.1523/JNEUROSCI.4003-12.2013

Ash, P. E., Bieniek, K. F., Gendron, T. F., Caulfield, T., Lin, W. L., DejesusHernandez, M., et al. (2013). Unconventional translation of C9ORF72 GGGGCC expansion generates insoluble polypeptides specific to c9FTD/ALS. Neuron 77, 639-646. doi: 10.1016/j.neuron.2013.02.004

Asli, N. S., and Kessel, M. (2010). Spatiotemporally restricted regulation of generic motor neuron programs by miR-196-mediated repression of Hoxb8. Dev. Biol. 344, 857-868. doi: 10.1016/j.ydbio.2010.06.003

Ayala, Y. M., De Conti, L., Avendano-Vazquez, S. E., Dhir, A., Romano, M., D'Ambrogio, A., et al. (2011). TDP-43 regulates its mRNA levels through a negative feedback loop. EMBO J. 30, 277-288. doi: 10.1038/emboj.2010.310

Bandyopadhyay, U., Cotney, J., Nagy, M., Oh, S., Leng, J., Mahajan, M., et al. (2013). RNA-Seq profiling of spinal cord motor neurons from a presymptomatic SOD1 ALS mouse. PLoS One 8:e53575. doi: 10.1371/journal.pone.0053575

Barker, H. V., Niblock, M., Lee, Y. B., Shaw, C. E., and Gallo, J. M. (2017). RNA misprocessing in C9orf72-linked neurodegeneration. Front. Cell. Neurosci. 11:195. doi: 10.3389/fncel.2017.00195

Bennett, C. F., and Swayze, E. E. (2010). RNA targeting therapeutics: molecular mechanisms of antisense oligonucleotides as a therapeutic platform. Annu. to modulation of gene and subsequent protein expression is an attractive therapeutic strategy. The preclinical testing of RNAbased therapies targeting SOD1 and C9orf72 mutations are indeed very promising. Similar studies are yet to be undertaken for FUS and TDP-43 mutations. RNA-based therapies could be considered in the future for the treatment of ALS.

\section{AUTHOR CONTRIBUTIONS}

SP contributed to the idea conception and overall review design. $\mathrm{ZB}$ and SP wrote the manuscript.

\section{FUNDING}

This work was supported by Canadian Institutes of Health Research (CIHR). SP was supported by an ALS Canada-Brain Canada Career Transition Award and Fonds de Recherche du Québec-Santé (FRQS) Junior 1 research award.

\section{ACKNOWLEDGMENTS}

The authors would like to thank Dr. Marie-Claude Belanger for her help with some of the illustrations of this manuscript.

Rev. Pharmacol. Toxicol. 50, 259-293. doi: 10.1146/annurev.pharmtox.010909. 105654

Bensimon, G., Lacomblez, L., and Meininger, V. (1994). A controlled trial of riluzole in amyotrophic lateral sclerosis. ALS/Riluzole Study Group. N. Engl. J. Med. 330, 585-591. doi: 10.1056/NEJM199403033300901

Bentmann, E., Neumann, M., Tahirovic, S., Rodde, R., Dormann, D., and Haass, C. (2012). Requirements for stress granule recruitment of fused in sarcoma (FUS) and TAR DNA-binding protein of $43 \mathrm{kDa}$ (TDP-43). J. Biol. Chem. 287, 23079-23094. doi: 10.1074/jbc.M111.328757

Bernat, V., and Disney, M. D. (2015). RNA structures as mediators of neurological diseases and as drug targets. Neuron 87, 28-46. doi: 10.1016/j.neuron.2015.06.012

Bhinge, A., Namboori, S. C., Bithell, A., Soldati, C., Buckley, N. J., and Stanton, L. W. (2016). MiR-375 is essential for human spinal motor neuron development and may be involved in motor neuron degeneration. Stem Cells 34, 124-134. doi: 10.1002/stem.2233

Biferi, M. G., Cohen-Tannoudji, M., Cappelletto, A., Giroux, B., Roda, M., Astord, S., et al. (2017). A new AAV10-U7-mediated gene therapy prolongs survival and restores function in an ALS mouse model. Mol. Ther. 25, 20382052. doi: 10.1016/j.ymthe.2017.05.017

Boillee, S., Vande Velde, C., and Cleveland, D. W. (2006). ALS: a disease of motor neurons and their nonneuronal neighbors. Neuron 52, 39-59. doi: 10.1016/j. neuron.2006.09.018

Borel, F., Gernoux, G., Cardozo, B., Metterville, J. P., Toro Cabrera, G. C., Song, L., et al. (2016). Therapeutic rAAVrh10 mediated SOD1 silencing in adult SOD1(G93A) mice and nonhuman primates. Hum. Gene Ther. 27, 19-31. doi: 10.1089/hum.2015.122

Bose, J. K., Wang, I. F., Hung, L., Tarn, W. Y., and Shen, C. K. (2008). TDP43 overexpression enhances exon 7 inclusion during the survival of motor neuron pre-mRNA splicing. J. Biol. Chem. 283, 28852-28859. doi: 10.1074/jbc. M805376200

Bowers, W. J., Breakefield, X. O., and Sena-Esteves, M. (2011). Genetic therapy for the nervous system. Hum. Mol. Genet. 20, R28-R41. doi: 10.1093/hmg/ddr110

Brooke, G. N., Culley, R. L., Dart, D. A., Mann, D. J., Gaughan, L., McCracken, S. R., et al. (2011). FUS/TLS is a novel mediator of androgen-dependent 
cell-cycle progression and prostate cancer growth. Cancer Res. 71, 914-924. doi: 10.1158/0008-5472.CAN-10-0874

Buratti, E., and Baralle, F. E. (2001). Characterization and functional implications of the RNA binding properties of nuclear factor TDP-43, a novel splicing regulator of CFTR exon 9. J. Biol. Chem. 276, 36337-36343. doi: 10.1074/jbc. M104236200

Buratti, E., and Baralle, F. E. (2008). Multiple roles of TDP-43 in gene expression, splicing regulation, and human disease. Front. Biosci. 13, 867-878. doi: 10.2741/ 2727

Buratti, E., Brindisi, A., Pagani, F., and Baralle, F. E. (2004). Nuclear factor TDP43 binds to the polymorphic TG repeats in CFTR intron 8 and causes skipping of exon 9: a functional link with disease penetrance. Am. J. Hum. Genet. 74, 1322-1325. doi: 10.1086/420978

Buratti, E., De Conti, L., Stuani, C., Romano, M., Baralle, M., and Baralle, F. (2010). Nuclear factor TDP-43 can affect selected microRNA levels. FEBS J. 277, 2268-2281. doi: 10.1111/j.1742-4658.2010.07643.x

Burnett, J. C., and Rossi, J. J. (2012). RNA-based therapeutics: current progress and future prospects. Chem. Biol. 19, 60-71. doi: 10.1016/j.chembiol.2011.12.008

Carthew, R. W., and Sontheimer, E. J. (2009). Origins and mechanisms of miRNAs and siRNAs. Cell 136, 642-655. doi: 10.1016/j.cell.2009.01.035

Castanotto, D., and Rossi, J. J. (2009). The promises and pitfalls of RNAinterference-based therapeutics. Nature 457, 426-433. doi: 10.1038/ nature 07758

Catalanotto, C., Cogoni, C., and Zardo, G. (2016). MicroRNA in control of gene expression: an overview of nuclear functions. Int. J. Mol. Sci. 17:E1712. doi: 10.3390/ijms17101712

Chakraborty, C., Sharma, A. R., Sharma, G., Doss, C. G. P., and Lee, S. S. (2017). Therapeutic miRNA and siRNA: moving from bench to clinic as next generation medicine. Mol. Ther. Nucleic Acids 8, 132-143. doi: 10.1016/j.omtn. 2017.06.005

Chang, J. C., Hazelett, D. J., Stewart, J. A., and Morton, D. B. (2014). Motor neuron expression of the voltage-gated calcium channel cacophony restores locomotion defects in a Drosophila, TDP-43 loss of function model of ALS. Brain Res. 1584, 39-51. doi: 10.1016/j.brainres.2013.11.019

Chen, H., Qian, K., Du, Z., Cao, J., Petersen, A., Liu, H., et al. (2014). Modeling ALS with iPSCs reveals that mutant SOD1 misregulates neurofilament balance in motor neurons. Cell Stem Cell 14, 796-809. doi: 10.1016/j.stem.2014.02.004

Chen, J. A., and Wichterle, H. (2012). Apoptosis of limb innervating motor neurons and erosion of motor pool identity upon lineage specific dicer inactivation. Front. Neurosci. 6:69. doi: 10.3389/fnins.2012.00069

Chen, J. F., Mandel, E. M., Thomson, J. M., Wu, Q., Callis, T. E., Hammond, S. M., et al. (2006). The role of microRNA-1 and microRNA-133 in skeletal muscle proliferation and differentiation. Nat. Genet. 38, 228-233. doi: 10.1038/ng1725

Chia, R., Chio, A., and Traynor, B. J. (2018). Novel genes associated with amyotrophic lateral sclerosis: diagnostic and clinical implications. Lancet Neurol. 17, 94-102. doi: 10.1016/S1474-4422(17)30401-5

Chiriboga, C. A., Swoboda, K. J., Darras, B. T., Iannaccone, S. T., Montes, J., De Vivo, D. C., et al. (2016). Results from a phase 1 study of nusinersen (ISIS$\operatorname{SMN}(\mathrm{Rx})$ ) in children with spinal muscular atrophy. Neurology 86, 890-897. doi: 10.1212/WNL.0000000000002445

Ciura, S., Lattante, S., Le Ber, I., Latouche, M., Tostivint, H., Brice, A., et al. (2013). Loss of function of C9orf72 causes motor deficits in a zebrafish model of amyotrophic lateral sclerosis. Ann. Neurol. 74, 180-187. doi: 10.1002/ana.23946

Coelho, M. B., Attig, J., Bellora, N., Konig, J., Hallegger, M., Kayikci, M., et al. (2015). Nuclear matrix protein Matrin3 regulates alternative splicing and forms overlapping regulatory networks with PTB. EMBO J. 34, 653-668. doi: 10. 15252/embj.201489852

Colombrita, C., Onesto, E., Megiorni, F., Pizzuti, A., Baralle, F. E., Buratti, E., et al. (2012). TDP-43 and FUS RNA-binding proteins bind distinct sets of cytoplasmic messenger RNAs and differently regulate their post-transcriptional fate in motoneuron-like cells. J. Biol. Chem. 287, 15635-15647. doi: 10.1074/jbc. M111.333450

Colombrita, C., Zennaro, E., Fallini, C., Weber, M., Sommacal, A., Buratti, E., et al. (2009). TDP-43 is recruited to stress granules in conditions of oxidative insult. J. Neurochem. 111, 1051-1061. doi: 10.1111/j.1471-4159.2009.06383.x

Connelly, C. M., Moon, M. H., and Schneekloth, J. S. Jr. (2016). The emerging role of RNA as a therapeutic target for small molecules. Cell Chem. Biol. 23, 1077-1090. doi: 10.1016/j.chembiol.2016.05.021
Cooper-Knock, J., Walsh, M. J., Higginbottom, A., Robin Highley, J., Dickman, M. J., Edbauer, D., et al. (2014). Sequestration of multiple RNA recognition motif-containing proteins by C9orf72 repeat expansions. Brain 137(Pt 7), 2040-2051. doi: 10.1093/brain/awu120

Corrado, L., Del Bo, R., Castellotti, B., Ratti, A., Cereda, C., Penco, S., et al. (2010). Mutations of FUS gene in sporadic amyotrophic lateral sclerosis. J. Med. Genet. 47, 190-194. doi: 10.1136/jmg.2009.071027

Couthouis, J., Hart, M. P., Shorter, J., DeJesus-Hernandez, M., Erion, R., Oristano, R., et al. (2011). A yeast functional screen predicts new candidate ALS disease genes. Proc. Natl. Acad. Sci. U.S.A. 108, 20881-20890. doi: 10.1073/pnas. 1109434108

Coyne, A. N., Siddegowda, B. B., Estes, P. S., Johannesmeyer, J., Kovalik, T., Daniel, S. G., et al. (2014). Futsch/MAP1B mRNA is a translational target of TDP-43 and is neuroprotective in a Drosophila model of amyotrophic lateral sclerosis. J. Neurosci. 34, 15962-15974. doi: 10.1523/JNEUROSCI.2526-14.2014

Da Cruz, S., and Cleveland, D. W. (2011). Understanding the role of TDP43 and FUS/TLS in ALS and beyond. Curr. Opin. Neurobiol. 21, 904-919. doi: $10.1016 /$ j.conb.2011.05.029

Daigle, J. G., Krishnamurthy, K., Ramesh, N., Casci, I., Monaghan, J., McAvoy, K., et al. (2016). Pur-alpha regulates cytoplasmic stress granule dynamics and ameliorates FUS toxicity. Acta Neuropathol. 131, 605-620. doi: 10.1007/s00401015-1530-0

Dajas-Bailador, F., Bonev, B., Garcez, P., Stanley, P., Guillemot, F., and Papalopulu, N. (2012). microRNA-9 regulates axon extension and branching by targeting Map1b in mouse cortical neurons. Nat. Neurosci. doi: 10.1038/nn.3082 [Epub ahead of print].

De Santis, R., Santini, L., Colantoni, A., Peruzzi, G., de Turris, V., Alfano, V., et al. (2017). FUS mutant human motoneurons display altered transcriptome and microRNA pathways with implications for ALS pathogenesis. Stem Cell Rep. 9, 1450-1462. doi: 10.1016/j.stemcr.2017.09.004

DeJesus-Hernandez, M., Kocerha, J., Finch, N., Crook, R., Baker, M., Desaro, P., et al. (2010). De novo truncating FUS gene mutation as a cause of sporadic amyotrophic lateral sclerosis. Hum. Mutat. 31, E1377-E1389. doi: 10.1002/ humu. 21241

DeJesus-Hernandez, M., Mackenzie, I. R., Boeve, B. F., Boxer, A. L., Baker, M., Rutherford, N. J., et al. (2011). Expanded GGGGCC hexanucleotide repeat in noncoding region of C9ORF72 causes chromosome 9p-linked FTD and ALS. Neuron 72, 245-256. doi: 10.1016/j.neuron.2011.09.011

Denli, A. M., Tops, B. B., Plasterk, R. H., Ketting, R. F., and Hannon, G. J. (2004). Processing of primary microRNAs by the Microprocessor complex. Nature 432, 231-235. doi: 10.1038/nature03049

D’Erchia, A. M., Gallo, A., Manzari, C., Raho, S., Horner, D. S., Chiara, M., et al. (2017). Massive transcriptome sequencing of human spinal cord tissues provides new insights into motor neuron degeneration in ALS. Sci. Rep. 7:10046. doi: 10.1038/s41598-017-10488-7

Deshaies, J. E., Shkreta, L., Moszczynski, A. J., Sidibe, H., Semmler, S., Fouillen, A., et al. (2018). TDP-43 regulates the alternative splicing of hnRNP A1 to yield an aggregation-prone variant in amyotrophic lateral sclerosis. Brain 141, 13201333. doi: 10.1093/brain/awy062

Di Antonio, M., Biffi, G., Mariani, A., Raiber, E. A., Rodriguez, R., and Balasubramanian, S. (2012). Selective RNA versus DNA G-quadruplex targeting by in situ click chemistry. Angew. Chem. Int. Ed. Engl. 51, 11073-11078. doi: $10.1002 /$ anie. 201206281

Di Salvio, M., Piccinni, V., Gerbino, V., Mantoni, F., Camerini, S., Lenzi, J., et al. (2015). Pur-alpha functionally interacts with FUS carrying ALS-associated mutations. Cell Death Dis. 6:e1943. doi: 10.1038/cddis.2015.295

Diaper, D. C., Adachi, Y., Sutcliffe, B., Humphrey, D. M., Elliott, C. J., Stepto, A., et al. (2013). Loss and gain of Drosophila TDP-43 impair synaptic efficacy and motor control leading to age-related neurodegeneration by loss-offunction phenotypes. Hum. Mol. Genet. 22, 1539-1557. doi: 10.1093/hmg/ ddt005

Dini Modigliani, S., Morlando, M., Errichelli, L., Sabatelli, M., and Bozzoni, I. (2014). An ALS-associated mutation in the FUS 3'-UTR disrupts a microRNAFUS regulatory circuitry. Nat. Commun. 5:4335. doi: 10.1038/ncomms 5335

Dirren, E., Aebischer, J., Rochat, C., Towne, C., Schneider, B. L., and Aebischer, P. (2015). SOD1 silencing in motoneurons or glia rescues neuromuscular function in ALS mice. Ann. Clin. Transl. Neurol. 2, 167-184. doi: 10.1002/acn3.162 
Disney, M. D. (2013). Rational design of chemical genetic probes of RNA function and lead therapeutics targeting repeating transcripts. Drug Discov. Today 18, 1228-1236. doi: 10.1016/j.drudis.2013.07.024

Donnelly, C. J., Zhang, P. W., Pham, J. T., Haeusler, A. R., Mistry, N. A., Vidensky, S., et al. (2013). RNA toxicity from the ALS/FTD C9ORF72 expansion is mitigated by antisense intervention. Neuron 80, 415-428. doi: 10.1016/j. neuron.2013.10.015

Dormann, D., Rodde, R., Edbauer, D., Bentmann, E., Fischer, I., Hruscha, A., et al. (2010). ALS-associated fused in sarcoma (FUS) mutations disrupt Transportin-mediated nuclear import. EMBO J. 29, 2841-2857. doi: 10.1038/emboj.2010.143

Dreyfuss, G., Matunis, M. J., Pinol-Roma, S., and Burd, C. G. (1993). hnRNP proteins and the biogenesis of mRNA. Annu. Rev. Biochem. 62, 289-321. doi: 10.1146/annurev.bi.62.070193.001445

Duggimpudi, S., Larsson, E., Nabhani, S., Borkhardt, A., and Hoell, J. I. (2015). The cell cycle regulator CCDC6 is a key target of RNA-binding protein EWS. PLoS One 10:e0119066. doi: 10.1371/journal.pone.0119066

Edbauer, D., Neilson, J. R., Foster, K. A., Wang, C. F., Seeburg, D. P., Batterton, M. N., et al. (2010). Regulation of synaptic structure and function by FMRPassociated microRNAs miR-125b and miR-132. Neuron 65, 373-384. doi: 10 . 1016/j.neuron.2010.01.005

Eitan, C., and Hornstein, E. (2016). Vulnerability of microRNA biogenesis in FTD-ALS. Brain Res. 1647, 105-111. doi: 10.1016/j.brainres.2015.12.063

Feiguin, F., Godena, V. K., Romano, G., D’Ambrogio, A., Klima, R., and Baralle, F. E. (2009). Depletion of TDP-43 affects Drosophila motoneurons terminal synapsis and locomotive behavior. FEBS Lett. 583, 1586-1592. doi: 10.1016/j. febslet.2009.04.019

Fellmann, C., and Lowe, S. W. (2014). Stable RNA interference rules for silencing. Nat. Cell Biol. 16, 10-18. doi: 10.1038/ncb2895

Fiesel, F. C., and Kahle, P. J. (2011). TDP-43 and FUS/TLS: cellular functions and implications for neurodegeneration. FEBS J. 278, 3550-3568. doi: 10.1111/j. 1742-4658.2011.08258.x

Finkel, R. S., Chiriboga, C. A., Vajsar, J., Day, J. W., Montes, J., De Vivo, D. C., et al. (2016). Treatment of infantile-onset spinal muscular atrophy with nusinersen: a phase 2, open-label, dose-escalation study. Lancet 388, 3017-3026. doi: 10.1016/ S0140-6736(16)31408-8

Fire, A., Xu, S., Montgomery, M. K., Kostas, S. A., Driver, S. E., and Mello, C. C. (1998). Potent and specific genetic interference by double-stranded RNA in Caenorhabditis elegans. Nature 391, 806-811. doi: 10.1038/35888

Forch, P., Puig, O., Kedersha, N., Martinez, C., Granneman, S., Seraphin, B., et al. (2000). The apoptosis-promoting factor TIA-1 is a regulator of alternative pre-mRNA splicing. Mol. Cell 6, 1089-1098. doi: 10.1016/S1097-2765(00)00107-6

Foust, K. D., Salazar, D. L., Likhite, S., Ferraiuolo, L., Ditsworth, D., Ilieva, H., et al. (2013). Therapeutic AAV9-mediated suppression of mutant SOD1 slows disease progression and extends survival in models of inherited ALS. Mol. Ther. 21, 2148-2159. doi: 10.1038/mt.2013.211

Fratta, P., Mizielinska, S., Nicoll, A. J., Zloh, M., Fisher, E. M., Parkinson, G., et al. (2012). C9orf72 hexanucleotide repeat associated with amyotrophic lateral sclerosis and frontotemporal dementia forms RNA G-quadruplexes. Sci. Rep. 2:1016. doi: 10.1038/srep01016

Freibaum, B. D., Chitta, R. K., High, A. A., and Taylor, J. P. (2010). Global analysis of TDP-43 interacting proteins reveals strong association with RNA splicing and translation machinery. J. Proteome Res. 9, 1104-1120. doi: 10.1021/pr901076y

Freibaum, B. D., Lu, Y., Lopez-Gonzalez, R., Kim, N. C., Almeida, S., Lee, K. H., et al. (2015). GGGGCC repeat expansion in C9orf72 compromises nucleocytoplasmic transport. Nature 525, 129-133. doi: 10.1038/nature14974

Freibaum, B. D., and Taylor, J. P. (2017). The role of dipeptide repeats in C9ORF72Related ALS-FTD. Front. Mol. Neurosci. 10:35. doi: 10.3389/fnmol.2017.00035

Fujioka, Y., Ishigaki, S., Masuda, A., Iguchi, Y., Udagawa, T., Watanabe, H., et al. (2013). FUS-regulated region- and cell-type-specific transcriptome is associated with cell selectivity in ALS/FTLD. Sci. Rep. 3:2388. doi: 10.1038/srep02388

Gao, G., Vandenberghe, L. H., and Wilson, J. M. (2005). New recombinant serotypes of AAV vectors. Curr. Gene Ther. 5, 285-297. doi: 10.2174/ 1566523054065057

Gendron, T. F., Bieniek, K. F., Zhang, Y. J., Jansen-West, K., Ash, P. E., Caulfield, T., et al. (2013). Antisense transcripts of the expanded C9ORF72 hexanucleotide repeat form nuclear RNA foci and undergo repeat-associated
non-ATG translation in c9FTD/ALS. Acta Neuropathol. 126, 829-844. doi: 10.1007/s00401-013-1192-8

Gijselinck, I., Van Mossevelde, S., van der Zee, J., Sieben, A., Engelborghs, S., De Bleecker, J., et al. (2016). The C9orf72 repeat size correlates with onset age of disease, DNA methylation and transcriptional downregulation of the promoter. Mol. Psychiatry 21, 1112-1124. doi: 10.1038/mp.2015.159

Gitler, A. D., and Tsuiji, H. (2016). There has been an awakening: emerging mechanisms of C9orf72 mutations in FTD/ALS. Brain Res. 1647, 19-29. doi: 10.1016/j.brainres.2016.04.004

Godena, V. K., Romano, G., Romano, M., Appocher, C., Klima, R., Buratti, E., et al. (2011). TDP-43 regulates Drosophila neuromuscular junctions growth by modulating Futsch/MAP1B levels and synaptic microtubules organization. PLoS One 6:e17808. doi: 10.1371/journal.pone.0017808

Haeusler, A. R., Donnelly, C. J., Periz, G., Simko, E. A., Shaw, P. G., Kim, M. S., et al. (2014). C9orf72 nucleotide repeat structures initiate molecular cascades of disease. Nature 507, 195-200. doi: 10.1038/nature13124

Haeusler, A. R., Donnelly, C. J., and Rothstein, J. D. (2016). The expanding biology of the C9orf72 nucleotide repeat expansion in neurodegenerative disease. Nat. Rev. Neurosci. 17, 383-395. doi: 10.1038/nrn.2016.38

Hammond, S. M., Boettcher, S., Caudy, A. A., Kobayashi, R., and Hannon, G. J. (2001). Argonaute2, a link between genetic and biochemical analyses of RNAi. Science 293, 1146-1150. doi: 10.1126/science.1064023

Handley, E. E., Pitman, K. A., Dawkins, E., Young, K. M., Clark, R. M., Jiang, T. C., et al. (2017). Synapse dysfunction of layer V pyramidal neurons precedes neurodegeneration in a mouse model of TDP-43 proteinopathies. Cereb. Cortex 27, 3630-3647. doi: 10.1093/cercor/bhw185

Haramati, S., Chapnik, E., Sztainberg, Y., Eilam, R., Zwang, R., Gershoni, N., et al. (2010). miRNA malfunction causes spinal motor neuron disease. Proc. Natl. Acad. Sci. U.S.A. 107, 13111-13116. doi: 10.1073/pnas.1006151107

Havens, M. A., and Hastings, M. L. (2016). Splice-switching antisense oligonucleotides as therapeutic drugs. Nucleic Acids Res. 44, 6549-6563. doi: 10.1093/nar/gkw533

Hawley, Z. C. E., Campos-Melo, D., Droppelmann, C. A., and Strong, M. J. (2017). MotomiRs: miRNAs in motor neuron function and disease. Front. Mol. Neurosci. 10:127. doi: 10.3389/fnmol.2017.00127

Hedlund, E., Karlsson, M., Osborn, T., Ludwig, W., and Isacson, O. (2010). Global gene expression profiling of somatic motor neuron populations with different vulnerability identify molecules and pathways of degeneration and protection. Brain 133(Pt 8), 2313-2330. doi: 10.1093/brain/awq167

Helferich, A. M., Brockmann, S. J., Reinders, J., Deshpande, D., Holzmann, K., Brenner, D., et al. (2018). Dysregulation of a novel miR-1825/TBCB/TUBA4A pathway in sporadic and familial ALS. Cell. Mol. Life Sci. 75, 4301-4319. doi: 10.1007/s00018-018-2873-1

Herzog, J. J., Deshpande, M., Shapiro, L., Rodal, A. A., and Paradis, S. (2017). TDP-43 misexpression causes defects in dendritic growth. Sci. Rep. 7:15656. doi: 10.1038/s41598-017-15914-4

Highley, J. R., Kirby, J., Jansweijer, J. A., Webb, P. S., Hewamadduma, C. A., Heath, P. R., et al. (2014). Loss of nuclear TDP-43 in amyotrophic lateral sclerosis (ALS) causes altered expression of splicing machinery and widespread dysregulation of RNA splicing in motor neurones. Neuropathol. Appl. Neurobiol. 40, 670-685. doi: 10.1111/nan. 12148

Hirano, A., Donnenfeld, H., Sasaki, S., and Nakano, I. (1984). Fine structural observations of neurofilamentous changes in amyotrophic lateral sclerosis. J. Neuropathol. Exp. Neurol. 43, 461-470. doi: 10.1097/00005072-19840900000001

Hoell, J. I., Larsson, E., Runge, S., Nusbaum, J. D., Duggimpudi, S., Farazi, T. A., et al. (2011). RNA targets of wild-type and mutant FET family proteins. Nat. Struct. Mol. Biol. 18, 1428-1431. doi: 10.1038/nsmb.2163

Huppert, J. L. (2008). Four-stranded nucleic acids: structure, function and targeting of G-quadruplexes. Chem. Soc. Rev. 37, 1375-1384. doi: 10.1039/b702491f

Hutvagner, G., McLachlan, J., Pasquinelli, A. E., Balint, E., Tuschl, T., and Zamore, P. D. (2001). A cellular function for the RNA-interference enzyme Dicer in the maturation of the let-7 small temporal RNA. Science 293, 834-838. doi: $10.1126 /$ science. 1062961

Hutvagner, G., and Zamore, P. D. (2002). A microRNA in a multiple-turnover RNAi enzyme complex. Science 297, 2056-2060. doi: 10.1126/science.1073827

Ibrahim, F., Maragkakis, M., Alexiou, P., Maronski, M. A., Dichter, M. A., and Mourelatos, Z. (2013). Identification of in vivo, conserved, 
TAF15 RNA binding sites reveals the impact of TAF15 on the neuronal transcriptome. Cell Rep. 3, 301-308. doi: 10.1016/j.celrep.2013. 01.021

Iguchi, Y., Katsuno, M., Niwa, J., Takagi, S., Ishigaki, S., Ikenaka, K., et al. (2013). Loss of TDP-43 causes age-dependent progressive motor neuron degeneration. Brain 136(Pt 5), 1371-1382. doi: 10.1093/brain/awt029

Iko, Y., Kodama, T. S., Kasai, N., Oyama, T., Morita, E. H., Muto, T., et al. (2004). Domain architectures and characterization of an RNA-binding protein, TLS. J. Biol. Chem. 279, 44834-44840. doi: 10.1074/jbc.M408552200

Ishigaki, S., Masuda, A., Fujioka, Y., Iguchi, Y., Katsuno, M., Shibata, A., et al. (2012). Position-dependent FUS-RNA interactions regulate alternative splicing events and transcriptions. Sci. Rep. 2:529. doi: 10.1038/srep00529

Jiang, J., Zhu, Q., Gendron, T. F., Saberi, S., McAlonis-Downes, M., Seelman, A., et al. (2016). Gain of toxicity from ALS/FTD-linked repeat expansions in C9ORF72 is alleviated by antisense oligonucleotides targeting GGGGCCcontaining RNAs. Neuron 90, 535-550. doi: 10.1016/j.neuron.2016.04.006

Johnston, R. J., and Hobert, O. (2003). A microRNA controlling left/right neuronal asymmetry in Caenorhabditis elegans. Nature 426, 845-849. doi: 10.1038/ nature 02255

Julien, J. P., Cote, F., and Collard, J. F. (1995). Mice overexpressing the human neurofilament heavy gene as a model of ALS. Neurobiol. Aging 16, 487-490; discussion 490-492. doi: 10.1016/0197-4580(94)00169-2

Julien, J. P., and Kriz, J. (2006). Transgenic mouse models of amyotrophic lateral sclerosis. Biochim. Biophys. Acta 1762, 1013-1024. doi: 10.1016/j.bbadis.2006. 03.006

Kabashi, E., Lin, L., Tradewell, M. L., Dion, P. A., Bercier, V., Bourgouin, P., et al. (2010). Gain and loss of function of ALS-related mutations of TARDBP (TDP-43) cause motor deficits in vivo. Hum. Mol. Genet. 19, 671-683. doi: $10.1093 / \mathrm{hmg} / \mathrm{ddp} 534$

Kabashi, E., Valdmanis, P. N., Dion, P., Spiegelman, D., McConkey, B. J., Vande Velde, C., et al. (2008). TARDBP mutations in individuals with sporadic and familial amyotrophic lateral sclerosis. Nat. Genet. 40, 572-574. doi: 10.1038/ng. 132

Kamelgarn, M., Chen, J., Kuang, L., Arenas, A., Zhai, J., Zhu, H., et al. (2016). Proteomic analysis of FUS interacting proteins provides insights into FUS function and its role in ALS. Biochim. Biophys. Acta 1862, 2004-2014. doi: 10.1016/j.bbadis.2016.07.015

Kawahara, Y., and Mieda-Sato, A. (2012). TDP-43 promotes microRNA biogenesis as a component of the Drosha and Dicer complexes. Proc. Natl. Acad. Sci. U.S.A. 109, 3347-3352. doi: 10.1073/pnas.1112427109

Kawamata, T., and Tomari, Y. (2010). Making RISC. Trends Biochem. Sci. 35, 368-376. doi: 10.1016/j.tibs.2010.03.009

Kedersha, N., and Anderson, P. (2007). Mammalian stress granules and processing bodies. Methods Enzymol. 431, 61-81. doi: 10.1016/S0076-6879(07)31005-7

Kenan, D. J., Query, C. C., and Keene, J. D. (1991). RNA recognition: towards identifying determinants of specificity. Trends Biochem. Sci. 16, 214-220. doi: 10.1016/0968-0004(91)90088-D

Ketting, R. F., Fischer, S. E., Bernstein, E., Sijen, T., Hannon, G. J., and Plasterk, R. H. (2001). Dicer functions in RNA interference and in synthesis of small RNA involved in developmental timing in C. elegans. Genes Dev. 15, 2654-2659. doi: 10.1101/gad.927801

Kiernan, M. C., Vucic, S., Cheah, B. C., Turner, M. R., Eisen, A., Hardiman, O., et al. (2011). Amyotrophic lateral sclerosis. Lancet 377, 942-955. doi: 10.1016/ S0140-6736(10)61156-7

Kino, Y., Washizu, C., Kurosawa, M., Yamada, M., Miyazaki, H., Akagi, T., et al. (2015). FUS/TLS deficiency causes behavioral and pathological abnormalities distinct from amyotrophic lateral sclerosis. Acta Neuropathol. Commun. 3:24. doi: 10.1186/s40478-015-0202-6

Kirby, J., Halligan, E., Baptista, M. J., Allen, S., Heath, P. R., Holden, H., et al. (2005). Mutant SOD1 alters the motor neuronal transcriptome: implications for familial ALS. Brain 128(Pt 7), 1686-1706. doi: 10.1093/brain/awh503

Kumimoto, E. L., Fore, T. R., and Zhang, B. (2013). Transcriptome profiling following neuronal and glial expression of ALS-linked SOD1 in Drosophila. G3 3, 695-708. doi: 10.1534/g3.113.005850

Kuznetsov, S. V., Ren, C. C., Woodson, S. A., and Ansari, A. (2008). Loop dependence of the stability and dynamics of nucleic acid hairpins. Nucleic Acids Res. 36, 1098-1112. doi: 10.1093/nar/gkm1083
Kwiatkowski, T. J. Jr., Bosco, D. A., Leclerc, A. L., Tamrazian, E., Vanderburg, C. R., Russ, C., et al. (2009). Mutations in the FUS/TLS gene on chromosome 16 cause familial amyotrophic lateral sclerosis. Science 323, 1205-1208. doi: 10.1126/science.1166066

Kwon, I., Xiang, S., Kato, M., Wu, L., Theodoropoulos, P., Wang, T., et al. (2014). Poly-dipeptides encoded by the C9orf72 repeats bind nucleoli, impede RNA biogenesis, and kill cells. Science 345, 1139-1145. doi: 10.1126/science.1254917

Lagier-Tourenne, C., Baughn, M., Rigo, F., Sun, S., Liu, P., Li, H. R., et al. (2013). Targeted degradation of sense and antisense C9orf72 RNA foci as therapy for ALS and frontotemporal degeneration. Proc. Natl. Acad. Sci. U.S.A. 110, E4530-E4539. doi: 10.1073/pnas.1318835110

Lagier-Tourenne, C., Polymenidou, M., Hutt, K. R., Vu, A. Q., Baughn, M., Huelga, S. C., et al. (2012). Divergent roles of ALS-linked proteins FUS/TLS and TDP43 intersect in processing long pre-mRNAs. Nat. Neurosci. 15, 1488-1497. doi: $10.1038 / \mathrm{nn} .3230$

Lee, Y., Ahn, C., Han, J., Choi, H., Kim, J., Yim, J., et al. (2003). The nuclear RNase III Drosha initiates microRNA processing. Nature 425, 415-419. doi: 10.1038/nature01957

Lee, Y. B., Chen, H. J., Peres, J. N., Gomez-Deza, J., Attig, J., Stalekar, M., et al. (2013). Hexanucleotide repeats in ALS/FTD form length-dependent RNA foci, sequester RNA binding proteins, and are neurotoxic. Cell Rep. 5, 1178-1186. doi: 10.1016/j.celrep.2013.10.049

Li, Y., Ray, P., Rao, E. J., Shi, C., Guo, W., Chen, X., et al. (2010). A Drosophila model for TDP-43 proteinopathy. Proc. Natl. Acad. Sci. U.S.A. 107, 3169-3174. doi: 10.1073/pnas.0913602107

Li, Z., Lu, Y., Xu, X. L., and Gao, F. B. (2013). The FTD/ALS-associated RNAbinding protein TDP-43 regulates the robustness of neuronal specification through microRNA-9a in Drosophila. Hum. Mol. Genet. 22, 218-225. doi: 10. $1093 / \mathrm{hmg} / \mathrm{dds} 420$

Liang, X. H., Shen, W., Sun, H., Migawa, M. T., Vickers, T. A., and Crooke, S. T. (2016). Translation efficiency of mRNAs is increased by antisense oligonucleotides targeting upstream open reading frames. Nat. Biotechnol. 34, 875-880. doi: 10.1038/nbt.3589

Lin, C. C., Liu, L. Z., Addison, J. B., Wonderlin, W. F., Ivanov, A. V., and Ruppert, J. M. (2011). A KLF4-miRNA-206 autoregulatory feedback loop can promote or inhibit protein translation depending upon cell context. Mol. Cell Biol. 31, 2513-2527. doi: 10.1128/MCB.01189-10

Lincecum, J. M., Vieira, F. G., Wang, M. Z., Thompson, K., De Zutter, G. S., Kidd, J., et al. (2010). From transcriptome analysis to therapeutic anti-CD40L treatment in the SOD1 model of amyotrophic lateral sclerosis. Nat. Genet. 42, 392-399. doi: 10.1038/ng.557

Liu-Yesucevitz, L., Bilgutay, A., Zhang, Y. J., Vanderweyde, T., Citro, A., Mehta, T., et al. (2010). Tar DNA binding protein-43 (TDP-43) associates with stress granules: analysis of cultured cells and pathological brain tissue. PLoS One 5:e13250. doi: 10.1371/journal.pone.0013250

Lu, L., Wang, S., Zheng, L., Li, X., Suswam, E. A., Zhang, X., et al. (2009). Amyotrophic lateral sclerosis-linked mutant SOD1 sequesters Hu antigen R (HuR) and TIA-1-related protein (TIAR): implications for impaired posttranscriptional regulation of vascular endothelial growth factor. J. Biol. Chem. 284, 33989-33998. doi: 10.1074/jbc.M109.067918

Lu, Y., Ferris, J., and Gao, F. B. (2009). Frontotemporal dementia and amyotrophic lateral sclerosis-associated disease protein TDP-43 promotes dendritic branching. Mol. Brain 2:30. doi: 10.1186/1756-6606-2-30

Lu, L., Zheng, L., Viera, L., Suswam, E., Li, Y., Li, X., et al. (2007). Mutant $\mathrm{Cu} / \mathrm{Zn}$-superoxide dismutase associated with amyotrophic lateral sclerosis destabilizes vascular endothelial growth factor mRNA and downregulates its expression. J. Neurosci. 27, 7929-7938. doi: 10.1523/JNEUROSCI.1877-07. 2007

Luxenhofer, G., Helmbrecht, M. S., Langhoff, J., Giusti, S. A., Refojo, D., and Huber, A. B. (2014). MicroRNA-9 promotes the switch from early-born to late-born motor neuron populations by regulating Onecut transcription factor expression. Dev. Biol. 386, 358-370. doi: 10.1016/j.ydbio.2013.12.023

Maguire, C. A., Ramirez, S. H., Merkel, S. F., Sena-Esteves, M., and Breakefield, X. O. (2014). Gene therapy for the nervous system: challenges and new strategies. Neurotherapeutics 11, 817-839. doi: 10.1007/s13311-014-0299-5

Maharjan, N., Kunzli, C., Buthey, K., and Saxena, S. (2017). C9ORF72 regulates stress granule formation and its deficiency impairs stress granule assembly, 
hypersensitizing cells to stress. Mol. Neurobiol. 54, 3062-3077. doi: 10.1007/ s12035-016-9850-1

Majounie, E., Renton, A. E., Mok, K., Dopper, E. G., Waite, A., Rollinson, S., et al. (2012). Frequency of the C9orf72 hexanucleotide repeat expansion in patients with amyotrophic lateral sclerosis and frontotemporal dementia: a cross-sectional study. Lancet Neurol. 11, 323-330. doi: 10.1016/S1474-4422(12) 70043-1

Mathis, S., and Le Masson, G. (2018). RNA-targeted therapies and amyotrophic lateral sclerosis. Biomedicines 6:E9. doi: 10.3390/biomedicines6010009

Matsushima, K., Isomoto, H., Yamaguchi, N., Inoue, N., Machida, H., Nakayama, T., et al. (2011). MiRNA-205 modulates cellular invasion and migration via regulating zinc finger E-box binding homeobox 2 expression in esophageal squamous cell carcinoma cells. J. Transl. Med. 9:30. doi: 10.1186/ 1479-5876-9-30

McDonald, K. K., Aulas, A., Destroismaisons, L., Pickles, S., Beleac, E., Camu, W., et al. (2011). TAR DNA-binding protein 43 (TDP-43) regulates stress granule dynamics via differential regulation of G3BP and TIA-1. Hum. Mol. Genet. 20, 1400-1410. doi: 10.1093/hmg/ddr021

Meissner, M., Lopato, S., Gotzmann, J., Sauermann, G., and Barta, A. (2003). Protooncoprotein TLS/FUS is associated to the nuclear matrix and complexed with splicing factors PTB, SRm160, and SR proteins. Exp. Cell Res. 283, 184-195. doi: 10.1016/S0014-4827(02)00046-0

Mendell, J. R., Al-Zaidy, S., Shell, R., Arnold, W. D., Rodino-Klapac, L. R., Prior, T. W., et al. (2017). Single-dose gene-replacement therapy for spinal muscular atrophy. N. Engl. J. Med. 377, 1713-1722. doi: 10.1056/NEJMoa1706198

Menzies, F. M., Grierson, A. J., Cookson, M. R., Heath, P. R., Tomkins, J., Figlewicz, D. A., et al. (2002). Selective loss of neurofilament expression in $\mathrm{Cu} / \mathrm{Zn}$ superoxide dismutase (SOD1) linked amyotrophic lateral sclerosis. J. Neurochem. 82, 1118-1128. doi: 10.1046/j.1471-4159.2002.01045.x

Mercado, P. A., Ayala, Y. M., Romano, M., Buratti, E., and Baralle, F. E. (2005). Depletion of TDP 43 overrides the need for exonic and intronic splicing enhancers in the human apoA-II gene. Nucleic Acids Res. 33, 6000-6010. doi: $10.1093 /$ nar/gki897

Miller, J. W., Urbinati, C. R., Teng-Umnuay, P., Stenberg, M. G., Byrne, B. J., Thornton, C. A., et al. (2000). Recruitment of human muscleblind proteins to $(\mathrm{CUG})(\mathrm{n})$ expansions associated with myotonic dystrophy. EMBO J. 19, 4439-4448. doi: 10.1093/emboj/19.17.4439

Miller, T. M., Kaspar, B. K., Kops, G. J., Yamanaka, K., Christian, L. J., Gage, F. H., et al. (2005). Virus-delivered small RNA silencing sustains strength in amyotrophic lateral sclerosis. Ann. Neurol. 57, 773-776. doi: 10.1002/ana.20453

Miller, T. M., Pestronk, A., David, W., Rothstein, J., Simpson, E., Appel, S. H., et al. (2013). An antisense oligonucleotide against SOD1 delivered intrathecally for patients with SOD1 familial amyotrophic lateral sclerosis: a phase 1, randomised, first-in-man study. Lancet Neurol. 12, 435-442. doi: 10.1016/ S1474-4422(13)70061-9

Moore, C. B., Guthrie, E. H., Huang, M. T., and Taxman, D. J. (2010). Short hairpin RNA (shRNA): design, delivery, and assessment of gene knockdown. Methods Mol. Biol. 629, 141-158. doi: 10.1007/978-1-60761-657-3_10

Mori, K., Lammich, S., Mackenzie, I. R., Forne, I., Zilow, S., Kretzschmar, H., et al. (2013a). hnRNP A3 binds to GGGGCC repeats and is a constituent of p62-positive/TDP43-negative inclusions in the hippocampus of patients with C9orf72 mutations. Acta Neuropathol. 125, 413-423. doi: 10.1007/s00401-0131088-7

Mori, K., Weng, S. M., Arzberger, T., May, S., Rentzsch, K., Kremmer, E., et al. (2013b). The C9orf72 GGGGCC repeat is translated into aggregating dipeptiderepeat proteins in FTLD/ALS. Science 339, 1335-1338. doi: 10.1126/science. 1232927

Morlando, M., Dini Modigliani, S., Torrelli, G., Rosa, A., Di Carlo, V., Caffarelli, E., et al. (2012). FUS stimulates microRNA biogenesis by facilitating co-transcriptional Drosha recruitment. EMBO J. 31, 4502-4510. doi: 10.1038/ emboj.2012.319

Naguibneva, I., Ameyar-Zazoua, M., Polesskaya, A., Ait-Si-Ali, S., Groisman, R., Souidi, M., et al. (2006). The microRNA miR-181 targets the homeobox protein Hox-A11 during mammalian myoblast differentiation. Nat. Cell Biol. 8, 278284. doi: $10.1038 /$ ncb 1373

Nakaya, T., Alexiou, P., Maragkakis, M., Chang, A., and Mourelatos, Z. (2013). FUS regulates genes coding for RNA-binding proteins in neurons by binding to their highly conserved introns. RNA 19, 498-509. doi: 10.1261/rna.037804.112
Narayanan, R. K., Mangelsdorf, M., Panwar, A., Butler, T. J., Noakes, P. G., and Wallace, R. H. (2013). Identification of RNA bound to the TDP-43 ribonucleoprotein complex in the adult mouse brain. Amyotroph. Lateral Scler. Frontotemporal Degener. 14, 252-260. doi: 10.3109/21678421.2012.734520

Neumann, M., Sampathu, D. M., Kwong, L. K., Truax, A. C., Micsenyi, M. C., Chou, T. T., et al. (2006). Ubiquitinated TDP-43 in frontotemporal lobar degeneration and amyotrophic lateral sclerosis. Science 314, 130-133. doi: 10. $1126 /$ science. 1134108

Nijssen, J., Comley, L. H., and Hedlund, E. (2017). Motor neuron vulnerability and resistance in amyotrophic lateral sclerosis. Acta Neuropathol. 133, 863-885. doi: 10.1007/s00401-017-1708-8

O'Rourke, J. G., Bogdanik, L., Muhammad, A., Gendron, T. F., Kim, K. J., Austin, A., et al. (2015). C9orf72 BAC transgenic mice display typical pathologic features of ALS/FTD. Neuron 88, 892-901. doi: 10.1016/j.neuron.2015.10.027

Orozco, D., Tahirovic, S., Rentzsch, K., Schwenk, B. M., Haass, C., and Edbauer, D. (2012). Loss of fused in sarcoma (FUS) promotes pathological Tau splicing. EMBO Rep. 13, 759-764. doi: 10.1038/embor.2012.90

Ostrowski, L. A., Hall, A. C., and Mekhail, K. (2017). Ataxin-2: from RNA control to human health and disease. Genes 8:E157. doi: 10.3390/genes8060157

Otaegi, G., Pollock, A., Hong, J., and Sun, T. (2011). MicroRNA miR-9 modifies motor neuron columns by a tuning regulation of FoxP1 levels in developing spinal cords. J. Neurosci. 31, 809-818. doi: 10.1523/JNEUROSCI.4330-10.2011

Pasinelli, P., and Brown, R. H. (2006). Molecular biology of amyotrophic lateral sclerosis: insights from genetics. Nat. Rev. Neurosci. 7, 710-723. doi: 10.1038/ nrn1971

Patten, S. A., Aggad, D., Martinez, J., Tremblay, E., Petrillo, J., Armstrong, G. A., et al. (2017). Neuroleptics as therapeutic compounds stabilizing neuromuscular transmission in amyotrophic lateral sclerosis. JCI Insight doi: 10.1172/jci. insight.97152 [Epub ahead of print].

Patten, S. A., Armstrong, G. A., Lissouba, A., Kabashi, E., Parker, J. A., and Drapeau, P. (2014). Fishing for causes and cures of motor neuron disorders. Dis. Model. Mech. 7, 799-809. doi: 10.1242/dmm.015719

Petrov, D., Mansfield, C., Moussy, A., and Hermine, O. (2017). ALS clinical trials review: 20 years of failure. are we any closer to registering a new treatment? Front. Aging Neurosci. 9:68. doi: 10.3389/fnagi.2017.00068

Picher-Martel, V., Valdmanis, P. N., Gould, P. V., Julien, J. P., and Dupre, N. (2016). From animal models to human disease: a genetic approach for personalized medicine in ALS. Acta Neuropathol. Commun. 4:70. doi: 10.1186/s40478-0160340-5

Polymenidou, M., Lagier-Tourenne, C., Hutt, K. R., Bennett, C. F., Cleveland, D. W., and Yeo, G. W. (2012). Misregulated RNA processing in amyotrophic lateral sclerosis. Brain Res. 1462, 3-15. doi: 10.1016/j.brainres.2012. 02.059

Polymenidou, M., Lagier-Tourenne, C., Hutt, K. R., Huelga, S. C., Moran, J., Liang, T. Y., et al. (2011). Long pre-mRNA depletion and RNA missplicing contribute to neuronal vulnerability from loss of TDP-43. Nat. Neurosci. 14, 459-468. doi: $10.1038 / \mathrm{nn} .2779$

Porta, S., Kwong, L. K., Trojanowski, J. Q., and Lee, V. M. (2015). Drosha inclusions are new components of dipeptide-repeat protein aggregates in FTLD-TDP and ALS C9orf72 expansion cases. J. Neuropathol. Exp. Neurol. 74, 380-387. doi: 10.1097/NEN.0000000000000182

Protter, D. S., and Parker, R. (2016). Principles and properties of stress granules. Trends Cell Biol. 26, 668-679. doi: 10.1016/j.tcb.2016.05.004

Prudencio, M., Belzil, V. V., Batra, R., Ross, C. A., Gendron, T. F., Pregent, L. J., et al. (2015). Distinct brain transcriptome profiles in C9orf72associated and sporadic ALS. Nat. Neurosci. 18, 1175-1182. doi: 10.1038/ nn. 4065

Ralph, G. S., Radcliffe, P. A., Day, D. M., Carthy, J. M., Leroux, M. A., Lee, D. C., et al. (2005). Silencing mutant SOD1 using RNAi protects against neurodegeneration and extends survival in an ALS model. Nat. Med. 11, 429-433. doi: $10.1038 / \mathrm{nm} 1205$

Ramaswami, M., Taylor, J. P., and Parker, R. (2013). Altered ribostasis: RNAprotein granules in degenerative disorders. Cell 154, 727-736. doi: 10.1016/j. cell.2013.07.038

Raoul, C., Abbas-Terki, T., Bensadoun, J. C., Guillot, S., Haase, G., Szulc, J., et al. (2005). Lentiviral-mediated silencing of SOD1 through RNA interference retards disease onset and progression in a mouse model of ALS. Nat. Med. 11, 423-428. doi: 10.1038/nm1207 
Rapp, T. B., Yang, L., Conrad, E. U. III, Mandahl, N., and Chansky, H. A. (2002). RNA splicing mediated by YB-1 is inhibited by TLS/CHOP in human myxoid liposarcoma cells. J. Orthop. Res. 20, 723-729. doi: 10.1016/S0736-0266(02) 00006-2

Rappsilber, J., Ryder, U., Lamond, A. I., and Mann, M. (2002). Large-scale proteomic analysis of the human spliceosome. Genome Res. 12, 1231-1245. doi: $10.1101 /$ gr.473902

Reber, S., Stettler, J., Filosa, G., Colombo, M., Jutzi, D., Lenzken, S. C., et al. (2016). Minor intron splicing is regulated by FUS and affected by ALS-associated FUS mutants. EMBO J. 35, 1504-1521. doi: 10.15252/embj.201593791

Renton, A. E., Majounie, E., Waite, A., Simon-Sanchez, J., Rollinson, S., Gibbs, J. R., et al. (2011). A hexanucleotide repeat expansion in C9ORF72 is the cause of chromosome 9p21-linked ALS-FTD. Neuron 72, 257-268. doi: 10.1016/j. neuron.2011.09.010

Rizzuti, M., Filosa, G., Melzi, V., Calandriello, L., Dioni, L., Bollati, V., et al. (2018). MicroRNA expression analysis identifies a subset of downregulated miRNAs in ALS motor neuron progenitors. Sci. Rep. 8:10105. doi: 10.1038/s41598-01828366- 1

Robertson, B., Dalby, A. B., Karpilow, J., Khvorova, A., Leake, D., and Vermeulen, A. (2010). Specificity and functionality of microRNA inhibitors. Silence 1:10. doi: 10.1186/1758-907X-1-10

Rogelj, B., Easton, L. E., Bogu, G. K., Stanton, L. W., Rot, G., Curk, T., et al. (2012). Widespread binding of FUS along nascent RNA regulates alternative splicing in the brain. Sci. Rep. 2:603. doi: 10.1038/srep00603

Rotem, N., Magen, I., Ionescu, A., Gershoni-Emek, N., Altman, T., Costa, C. J., et al. (2017). ALS along the axons - expression of coding and noncoding RNA differs in axons of ALS models. Sci. Rep. 7:44500. doi: 10.1038/srep 44500

Sama, R. R., Ward, C. L., Kaushansky, L. J., Lemay, N., Ishigaki, S., Urano, F., et al. (2013). FUS/TLS assembles into stress granules and is a prosurvival factor during hyperosmolar stress. J. Cell. Physiol. 228, 2222-2231. doi: 10.1002/jcp. 24395

Sareen, D., O’Rourke, J. G., Meera, P., Muhammad, A. K., Grant, S., Simpkinson, M., et al. (2013). Targeting RNA foci in iPSC-derived motor neurons from ALS patients with a C9ORF72 repeat expansion. Sci. Transl. Med. 5:208ra149. doi: 10.1126/scitranslmed.3007529

Scekic-Zahirovic, J., Sendscheid, O., El Oussini, H., Jambeau, M., Sun, Y., Mersmann, S., et al. (2016). Toxic gain of function from mutant FUS protein is crucial to trigger cell autonomous motor neuron loss. EMBO J. 35, 1077-1097. doi: $10.15252 / \mathrm{embj} .201592559$

Schoch, K. M., and Miller, T. M. (2017). Antisense oligonucleotides: translation from mouse models to human neurodegenerative diseases. Neuron 94, 10561070. doi: 10.1016/j.neuron.2017.04.010

Schwartz, J. C., Ebmeier, C. C., Podell, E. R., Heimiller, J., Taatjes, D. J., and Cech, T. R. (2012). FUS binds the CTD of RNA polymerase II and regulates its phosphorylation at Ser2. Genes Dev. 26, 2690-2695. doi: 10.1101/gad.204602. 112

Schwarz, D. S., Hutvagner, G., Du, T., Xu, Z., Aronin, N., and Zamore, P. D. (2003). Asymmetry in the assembly of the RNAi enzyme complex. Cell 115, 199-208. doi: 10.1016/S0092-8674(03)00759-1

Scoles, D. R., and Pulst, S. M. (2018). Oligonucleotide therapeutics in neurodegenerative diseases. RNA Biol. 15, 707-714. doi: 10.1080/15476286. 2018.1454812

Scoto, M., Finkel, R. S., Mercuri, E., and Muntoni, F. (2017). Therapeutic approaches for spinal muscular atrophy (SMA). Gene Ther. 24, 514-519. doi: 10.1038 /gt.2017.45

Sellier, C., Freyermuth, F., Tabet, R., Tran, T., He, F., Ruffenach, F., et al. (2013). Sequestration of DROSHA and DGCR8 by expanded CGG RNA repeats alters microRNA processing in fragile X-associated tremor/ataxia syndrome. Cell Rep. 3, 869-880. doi: 10.1016/j.celrep.2013.02.004

Selvaraj, B. T., Livesey, M. R., Zhao, C., Gregory, J. M., James, O. T., Cleary, E. M., et al. (2018). C9ORF72 repeat expansion causes vulnerability of motor neurons to $\mathrm{Ca}^{2+}$-permeable AMPA receptor-mediated excitotoxicity. Nat. Commun. 9:347. doi: 10.1038/s41467-017-02729-0

Sephton, C. F., Cenik, C., Kucukural, A., Dammer, E. B., Cenik, B., Han, Y., et al. (2011). Identification of neuronal RNA targets of TDP-43-containing ribonucleoprotein complexes. J. Biol. Chem. 286, 1204-1215. doi: 10.1074/jbc. M110.190884
Shi, K. Y., Mori, E., Nizami, Z. F., Lin, Y., Kato, M., Xiang, S., et al. (2017). Toxic PRn poly-dipeptides encoded by the C9orf72 repeat expansion block nuclear import and export. Proc. Natl. Acad. Sci. U.S.A. 114, E1111-E1117. doi: 10.1073/pnas.162029 3114

Shiga, A., Ishihara, T., Miyashita, A., Kuwabara, M., Kato, T., Watanabe, N., et al. (2012). Alteration of POLDIP3 splicing associated with loss of function of TDP43 in tissues affected with ALS. PLoS One 7:e43120. doi: 10.1371/journal.pone. 0043120

Simone, R., Balendra, R., Moens, T. G., Preza, E., Wilson, K. M., Heslegrave, A., et al. (2018). G-quadruplex-binding small molecules ameliorate C9orf72 FTD/ALS pathology in vitro and in vivo. EMBO Mol. Med. 10, 22-31. doi: 10.15252/emmm.201707850

Simone, R., Fratta, P., Neidle, S., Parkinson, G. N., and Isaacs, A. M. (2015). G-quadruplexes: emerging roles in neurodegenerative diseases and the noncoding transcriptome. FEBS Lett. 589, 1653-1668. doi: 10.1016/j.febslet.2015. 05.003

Simon-Sanchez, J., Dopper, E. G., Cohn-Hokke, P. E., Hukema, R. K., Nicolaou, N., Seelaar, H., et al. (2012). The clinical and pathological phenotype of C9ORF72 hexanucleotide repeat expansions. Brain 135(Pt 3), 723-735. doi: 10.1093/ brain/awr353

Smith, J. K., and Agbandje-McKenna, M. (2018). Creating an arsenal of Adenoassociated virus (AAV) gene delivery stealth vehicles. PLoS Pathog. 14:e1006929. doi: 10.1371/journal.ppat.1006929

Smith, R. A., Miller, T. M., Yamanaka, K., Monia, B. P., Condon, T. P., Hung, G., et al. (2006). Antisense oligonucleotide therapy for neurodegenerative disease. J. Clin. Invest. 116, 2290-2296. doi: 10.1172/JCI25424

Sreedharan, J., Blair, I. P., Tripathi, V. B., Hu, X., Vance, C., Rogelj, B., et al. (2008). TDP-43 mutations in familial and sporadic amyotrophic lateral sclerosis. Science 319, 1668-1672. doi: 10.1126/science.1154584

Stallings, N. R., Puttaparthi, K., Dowling, K. J., Luther, C. M., Burns, D. K., Davis, K., et al. (2013). TDP-43, an ALS linked protein, regulates fat deposition and glucose homeostasis. PLoS One 8:e71793. doi: 10.1371/journal.pone. 0071793

Stallings, N. R., Puttaparthi, K., Luther, C. M., Burns, D. K., and Elliott, J. L. (2010). Progressive motor weakness in transgenic mice expressing human TDP-43. Neurobiol. Dis. 40, 404-414. doi: 10.1016/j.nbd.2010.06.017

Stephenson, M. L., and Zamecnik, P. C. (1978). Inhibition of Rous sarcoma viral RNA translation by a specific oligodeoxyribonucleotide. Proc. Natl. Acad. Sci. U.S.A. 75, 285-288. doi: 10.1073/pnas.75.1.285

Strong, M. J., Volkening, K., Hammond, R., Yang, W., Strong, W., LeystraLantz, C., et al. (2007). TDP43 is a human low molecular weight neurofilament (hNFL) mRNA-binding protein. Mol. Cell. Neurosci. 35, 320-327. doi: 10.1016/ j.mcn.2007.03.007

Su, Z., Zhang, Y., Gendron, T. F., Bauer, P. O., Chew, J., Yang, W. Y., et al. (2014). Discovery of a biomarker and lead small molecules to target r(GGGGCC)associated defects in c9FTD/ALS. Neuron 83, 1043-1050. doi: 10.1016/j.neuron. 2014.07.041

Sun, K., Westholm, J. O., Tsurudome, K., Hagen, J. W., Lu, Y., Kohwi, M., et al. (2012). Neurophysiological defects and neuronal gene deregulation in Drosophila mir-124 mutants. PLoS Genet. 8:e1002515. doi: 10.1371/journal. pgen. 1002515

Sun, S., Sun, Y., Ling, S. C., Ferraiuolo, L., McAlonis-Downes, M., Zou, Y., et al. (2015). Translational profiling identifies a cascade of damage initiated in motor neurons and spreading to glia in mutant SOD1-mediated ALS. Proc. Natl. Acad. Sci. U.S.A. 112, E6993-E7002. doi: 10.1073/pnas.1520639112

Suzuki, H., Shibagaki, Y., Hattori, S., and Matsuoka, M. (2018). The prolinearginine repeat protein linked to C9-ALS/FTD causes neuronal toxicity by inhibiting the DEAD-box RNA helicase-mediated ribosome biogenesis. Cell Death Dis. 9:975. doi: 10.1038/s41419-018-1028-5

Tan, A. Y., and Manley, J. L. (2010). TLS inhibits RNA polymerase III transcription. Mol. Cell Biol. 30, 186-196. doi: 10.1128/MCB.00884-09

Tan, A. Y., Riley, T. R., Coady, T., Bussemaker, H. J., and Manley, J. L. (2012). TLS/FUS (translocated in liposarcoma/fused in sarcoma) regulates target gene transcription via single-stranded DNA response elements. Proc. Natl. Acad. Sci. U.S.A. 109, 6030-6035. doi: 10.1073/pnas.1203028109

Thiebes, K. P., Nam, H., Cambronne, X. A., Shen, R., Glasgow, S. M., Cho, H. H., et al. (2015). miR-218 is essential to establish motor neuron fate 
as a downstream effector of Isl1-Lhx3. Nat. Commun. 6:7718. doi: 10.1038/ ncomms 8718

Thomsen, G. M., Gowing, G., Latter, J., Chen, M., Vit, J. P., Staggenborg, K., et al. (2014). Delayed disease onset and extended survival in the SOD1G93A rat model of amyotrophic lateral sclerosis after suppression of mutant SOD1 in the motor cortex. J. Neurosci. 34, 15587-15600. doi: 10.1523/JNEUROSCI.2037-14. 2014

Tiwari, A., Xu, Z., and Hayward, L. J. (2005). Aberrantly increased hydrophobicity shared by mutants of $\mathrm{Cu}, \mathrm{Zn}$-superoxide dismutase in familial amyotrophic lateral sclerosis. J. Biol. Chem. 280, 29771-29779. doi: 10.1074/jbc.M50403 9200

Tollervey, J. R., Curk, T., Rogelj, B., Briese, M., Cereda, M., Kayikci, M., et al. (2011). Characterizing the RNA targets and position-dependent splicing regulation by TDP-43. Nat. Neurosci. 14, 452-458. doi: 10.1038/nn.2778

Trias, E., Ibarburu, S., Barreto-Nunez, R., Babdor, J., Maciel, T. T., Guillo, M., et al. (2016). Post-paralysis tyrosine kinase inhibition with masitinib abrogates neuroinflammation and slows disease progression in inherited amyotrophic lateral sclerosis. J. Neuroinflammation 13:177. doi: 10.1186/s12974-016-0620-9

Truesdell, S. S., Mortensen, R. D., Seo, M., Schroeder, J. C., Lee, J. H., LeTonqueze, O., et al. (2012). MicroRNA-mediated mRNA translation activation in quiescent cells and oocytes involves recruitment of a nuclear microRNP. Sci. Rep. 2:842. doi: 10.1038/srep00842

Vaccaro, A., Tauffenberger, A., Aggad, D., Rouleau, G., Drapeau, P., and Parker, J. A. (2012). Mutant TDP-43 and FUS cause age-dependent paralysis and neurodegeneration in C. elegans. PLoS One 7:e31321. doi: 10.1371/journal.pone. 0031321

Van Deerlin, V. M., Leverenz, J. B., Bekris, L. M., Bird, T. D., Yuan, W., Elman, L. B., et al. (2008). TARDBP mutations in amyotrophic lateral sclerosis with TDP43 neuropathology: a genetic and histopathological analysis. Lancet Neurol. 7, 409-416. doi: 10.1016/S1474-4422(08)70071-1

Vance, C., Rogelj, B., Hortobagyi, T., De Vos, K. J., Nishimura, A. L., Sreedharan, J., et al. (2009). Mutations in FUS, an RNA processing protein, cause familial amyotrophic lateral sclerosis type 6. Science 323, 1208-1211. doi: 10.1126/ science. 1165942

Vasudevan, S. (2012). Posttranscriptional upregulation by microRNAs. Wiley Interdiscip. Rev. RNA 3, 311-330. doi: 10.1002/wrna.121

Vasudevan, S., Tong, Y., and Steitz, J. A. (2007). Switching from repression to activation: microRNAs can up-regulate translation. Science 318, 1931-1934. doi: $10.1126 /$ science. 1149460

Vickers, T. A., and Crooke, S. T. (2014). Antisense oligonucleotides capable of promoting specific target mRNA reduction via competing RNase H1dependent and independent mechanisms. PLoS One 9:e108625. doi: 10.1371/ journal.pone. 0108625

Volkening, K., Leystra-Lantz, C., Yang, W., Jaffee, H., and Strong, M. J. (2009). Tar DNA binding protein of $43 \mathrm{kDa}$ (TDP-43), 14-3-3 proteins and copper/zinc superoxide dismutase (SOD1) interact to modulate NFL mRNA stability. Implications for altered RNA processing in amyotrophic lateral sclerosis (ALS). Brain Res. 1305, 168-182. doi: 10.1016/j.brainres.2009. 09.105

Wang, H., Ghosh, A., Baigude, H., Yang, C. S., Qiu, L., Xia, X., et al. (2008). Therapeutic gene silencing delivered by a chemically modified small interfering RNA against mutant SOD1 slows amyotrophic lateral sclerosis progression. J. Biol. Chem. 283, 15845-15852. doi: 10.1074/jbc.M8008 34200

Wang, I. F., Wu, L. S., Chang, H. Y., and Shen, C. K. (2008). TDP-43, the signature protein of FTLD-U, is a neuronal activity-responsive factor. J. Neurochem. 105, 797-806. doi: 10.1111/j.1471-4159.2007.05190.x

Wang, X., Arai, S., Song, X., Reichart, D., Du, K., Pascual, G., et al. (2008). Induced ncRNAs allosterically modify RNA-binding proteins in cis to inhibit transcription. Nature 454, 126-130. doi: 10.1038/nature06992

Wang, H., Yang, B., Qiu, L., Yang, C., Kramer, J., Su, Q., et al. (2014). Widespread spinal cord transduction by intrathecal injection of rAAV delivers efficacious RNAi therapy for amyotrophic lateral sclerosis. Hum. Mol. Genet. 23, 668-681. doi: $10.1093 / \mathrm{hmg} / \mathrm{ddt} 454$

Wegorzewska, I., Bell, S., Cairns, N. J., Miller, T. M., and Baloh, R. H. (2009). TDP43 mutant transgenic mice develop features of ALS and frontotemporal lobar degeneration. Proc. Natl. Acad. Sci. U.S.A. 106, 18809-18814. doi: 10.1073/pnas. 0908767106
Weinmann, J., and Grimm, D. (2017). Next-generation AAV vectors for clinical use: an ever-accelerating race. Virus Genes 53, 707-713. doi: 10.1007/s11262017-1502-7

Winton, M. J., Igaz, L. M., Wong, M. M., Kwong, L. K., Trojanowski, J. Q., and Lee, V. M. (2008a). Disturbance of nuclear and cytoplasmic TAR DNA-binding protein (TDP-43) induces disease-like redistribution, sequestration, and aggregate formation. J. Biol. Chem. 283, 13302-13309. doi: 10.1074/jbc.M80034 2200

Winton, M. J., Van Deerlin, V. M., Kwong, L. K., Yuan, W., Wood, E. M., Yu, C. E., et al. (2008b). A90V TDP-43 variant results in the aberrant localization of TDP-43 in vitro. FEBS Lett. 582, 2252-2256. doi: 10.1016/j.febslet.2008. 05.024

Wong, N. K., He, B. P., and Strong, M. J. (2000). Characterization of neuronal intermediate filament protein expression in cervical spinal motor neurons in sporadic amyotrophic lateral sclerosis (ALS). J. Neuropathol. Exp. Neurol. 59, 972-982. doi: 10.1093/jnen/59.11.972

Wu, R., Wang, H., Xia, X., Zhou, H., Liu, C., Castro, M., et al. (2009). Nerve injection of viral vectors efficiently transfers transgenes into motor neurons and delivers RNAi therapy against ALS. Antioxid. Redox Signal. 11, 1523-1534. doi: 10.1089/ARS.2009.2618

Xu, Z., Cork, L. C., Griffin, J. W., and Cleveland, D. W. (1993). Increased expression of neurofilament subunit NF-L produces morphological alterations that resemble the pathology of human motor neuron disease. Cell 73, 23-33. doi: 10.1016/0092-8674(93)90157-L

Xu, Z., Poidevin, M., Li, X., Li, Y., Shu, L., Nelson, D. L., et al. (2013). Expanded GGGGCC repeat RNA associated with amyotrophic lateral sclerosis and frontotemporal dementia causes neurodegeneration. Proc. Natl. Acad. Sci. U.S.A. 110, 7778-7783. doi: 10.1073/pnas.1219643110

Yamasaki, S., Ivanov, P., Hu, G. F., and Anderson, P. (2009). Angiogenin cleaves tRNA and promotes stress-induced translational repression. J. Cell Biol. 185, $35-42$.

Yamazaki, T., Chen, S., Yu, Y., Yan, B., Haertlein, T. C., Carrasco, M. A., et al. (2012). FUS-SMN protein interactions link the motor neuron diseases ALS and SMA. Cell Rep. 2, 799-806. doi: 10.1016/j.celrep.2012.08.025

Yang, C., Wang, H., Qiao, T., Yang, B., Aliaga, L., Qiu, L., et al. (2014). Partial loss of TDP-43 function causes phenotypes of amyotrophic lateral sclerosis. Proc. Natl. Acad. Sci. U.S.A. 111, E1121-E1129. doi: 10.1073/pnas.1322 641111

Yasuda, K., Zhang, H., Loiselle, D., Haystead, T., Macara, I. G., and Mili, S. (2013). The RNA-binding protein Fus directs translation of localized mRNAs in APC-RNP granules. J. Cell Biol. 203, 737-746. doi: 10.1083/jcb.201306058

Yekta, S., Shih, I. H., and Bartel, D. P. (2004). MicroRNA-directed cleavage of HOXB8 mRNA. Science 304, 594-596. doi: 10.1126/science. 1097434

Yi, R., Qin, Y., Macara, I. G., and Cullen, B. R. (2003). Exportin-5 mediates the nuclear export of pre-microRNAs and short hairpin RNAs. Genes Dev. 17, 3011-3016. doi: 10.1101/gad.1158803

Yokota, T., Miyagishi, M., Hino, T., Matsumura, R., Tasinato, A., Urushitani, M., et al. (2004). siRNA-based inhibition specific for mutant SOD1 with single nucleotide alternation in familial ALS, compared with ribozyme and DNA enzyme. Biochem. Biophys. Res. Commun. 314, 283-291. doi: 10.1016/j.bbrc. 2003.12.098

Yu, Y., Chi, B., Xia, W., Gangopadhyay, J., Yamazaki, T., WinkelbauerHurt, M. E., et al. (2015). U1 snRNP is mislocalized in ALS patient fibroblasts bearing NLS mutations in FUS and is required for motor neuron outgrowth in zebrafish. Nucleic Acids Res. 43, 3208-3218. doi: 10.1093/nar/ gkv157

Zhang, K., Coyne, A. N., and Lloyd, T. E. (2018a). Drosophila models of amyotrophic lateral sclerosis with defects in RNA metabolism. Brain Res. 1693(Pt A), 109-120. doi: 10.1016/j.brainres.2018.04.043

Zhang, K., Daigle, J. G., Cunningham, K. M., Coyne, A. N., Ruan, K., Grima, J. C., et al. (2018b). Stress granule assembly disrupts nucleocytoplasmic transport. Cell 173, 958-971.e17. doi: 10.1016/j.cell.2018.03.025

Zhang, Y. J., Gendron, T. F., Ebbert, M. T. W., O’Raw, A. D., Yue, M., JansenWest, K., et al. (2018c). Poly(GR) impairs protein translation and stress granule dynamics in C9orf72-associated frontotemporal dementia and amyotrophic lateral sclerosis. Nat. Med. 24, 1136-1142. doi: 10.1038/s41591-0180071-1 
Zhang, K., Donnelly, C. J., Haeusler, A. R., Grima, J. C., Machamer, J. B., Steinwald, P., et al. (2015). The C9orf72 repeat expansion disrupts nucleocytoplasmic transport. Nature 525, 56-61. doi: 10.1038/nature14973

Zhang, Z., Almeida, S., Lu, Y., Nishimura, A. L., Peng, L., Sun, D., et al. (2013). Downregulation of microRNA-9 in iPSC-derived neurons of FTD/ALS patients with TDP-43 mutations. PLoS One 8:e76055. doi: 10.1371/journal. pone. 0076055

Zhou, F., Guan, Y., Chen, Y., Zhang, C., Yu, L., Gao, H., et al. (2013). miRNA-9 expression is upregulated in the spinal cord of G93A-SOD1 transgenic mice. Int. J. Clin. Exp. Pathol. 6, 1826-1838.

Zhou, Y., Liu, S., Liu, G., Ozturk, A., and Hicks, G. G. (2013). ALSassociated FUS mutations result in compromised FUS alternative splicing and autoregulation. PLoS Genet. 9:e1003895. doi: 10.1371/journal.pgen.100 3895
Zhou, Z., Licklider, L. J., Gygi, S. P., and Reed, R. (2002). Comprehensive proteomic analysis of the human spliceosome. Nature 419, 182-185. doi: 10. 1038/nature01031

Conflict of Interest Statement: The authors declare that the research was conducted in the absence of any commercial or financial relationships that could be construed as a potential conflict of interest.

Copyright (c) 2019 Butti and Patten. This is an open-access article distributed under the terms of the Creative Commons Attribution License (CC BY). The use, distribution or reproduction in other forums is permitted, provided the original author(s) and the copyright owner(s) are credited and that the original publication in this journal is cited, in accordance with accepted academic practice. No use, distribution or reproduction is permitted which does not comply with these terms. 